\title{
Neuroimaging-based Individualized Prediction of Cognition and Behavior for Mental Disorders and Health: Methods and Promises
}

Jing Sui ${ }^{1,2,3,4^{* \#}}$, Rongtao Jiang ${ }^{1,2 \#}$, Juan Bustillo ${ }^{5}$, Vince Calhoun ${ }^{4 *}$

${ }^{1}$ Brainnetome Center and National Laboratory of Pattern Recognition, Institute of Automation, Chinese Academy of Sciences, Beijing, China, 100190

${ }^{2}$ University of Chinese Academy of Sciences, Beijing, China, 100049

${ }^{3}$ CAS Center for Excellence in Brain Science and Intelligence Technology, Institute of Automation, Chinese Academy of Sciences, Beijing, China, 100190

${ }^{4}$ Tri-institutional Center for Translational Research in Neuroimaging and Data Science (TReNDS), Georgia State University, Georgia Institute of Technology, and Emory University, Atlanta, GA, USA, 30303

${ }^{5}$ Department of Psychiatry, University of New Mexico, Albuquerque, NM, USA, 87131

Running title: Identify neuromarkers using predictive modeling

\section{Address for Correspondence:}

Vince Calhoun Ph.D. vcalhoun@gsu.edu and Jing Sui Ph.D. jsui@gsu.edu

Tri-institutional Center for Translational Research in Neuroimaging and Data Science (TReNDS), Georgia State University, Georgia Institute of Technology, and Emory University, Atlanta, GA, USA, 30303

\# Jing Sui and Rongtao Jiang contribute equally as co-first authors

Keywords: Biomarker, Cognition, Individualized Prediction, Multivariate Analyses, Regression, Mental Disorder

Main text Word count: 3935

Abstract word count: 189

Number of references: 102

Number of Figures: 4

Number of Tables: 0

Number of Supplementary Files: 1 


\begin{abstract}
The neuroimaging community has witnessed a paradigm shift in biomarker discovery from using traditional univariate brain mapping approaches to multivariate predictive models, allowing the field to move towards a translational neuroscience era. Regression-based multivariate models (hereafter "predictive modeling") provide a powerful and widely-used approach to predict human behavior with neuroimaging features. These studies maintain a focus on decoding individual differences in a continuously behavioral phenotype from neuroimaging data, opening up an exciting opportunity to describe the human brain at the single-subject level. In this survey, we provide an overview of recent studies that utilize machine learning approaches to identify neuroimaging predictors over the past decade. We first review regression-based approaches and highlight connectome-based predictive modeling (CPM), which has grown in popularity in recent years. Next, we systematically describe recent representative studies using these tools in the context of cognitive function, symptom severity, personality traits and emotion processing. Finally, we highlight a few challenges related to combining multimodal data, longitudinal prediction, external validations and the employment of deep learning methods that have emerged from our review of the existing literature, as well as present some promising and challenging future directions.
\end{abstract}


bioRxiv preprint doi: https://doi.org/10.1101/2020.02.22.961136; this version posted February 25, 2020. The copyright holder for this preprint (which was not certified by peer review) is the author/funder, who has granted bioRxiv a license to display the preprint in perpetuity. It is made available under aCC-BY-NC-ND 4.0 International license.

\section{Introduction}

A biomarker, or biological marker, generally refers to a measurable indicator of normal biological processes, pathogenic processes, or pharmacologic responses to a therapeutic intervention (1). The ultimate goal of developing biomarkers is to perform individual-level predictions of human behavior that may eventually benefit educational or clinical practices in real-world settings (2). However, most neuroimaging findings from the published studies cannot be easily translated into tools with practical utility. On one hand, many existing studies primarily focus on group-level mapping using univariate analytical techniques across a massive number of isolated brain measurements, e.g., either detecting brain features showing significant group differences between healthy controls and patients with brain disorders using statistical inferences, or establishing the brain-behavior relationship using correlational analysis. Despite the fact that these investigations have offered valuable insights into the human brain, such studies may dilute the considerable heterogeneity within group that is crucial for understanding the related neurobiological basis (3). On the other hand, due in part to a lack of out-of-sample validation, group-level inferences often overfit to both the signal and noise in a specific dataset. Therefore, the generalizability of such group-level findings to new individuals remains unknown (4). In addition, traditional univariate research focuses on explaining the neural correlates of observed behavior, rather than predicting future behavior based on neuro(5)imaging signatures, the latter being an important aspect of moving towards a translational neuroscience era (6).

Recent years have witnessed a paradigm shift in biomarker discovery from using traditional univariate brain mapping techniques to multivariate predictive models for an individual (7). Different from conventional approaches, machine learning-based methods can establish integrated brain models by taking into account the multivariate nature of diverse brain function or structure measurements across the whole brain (8), which may open up an exciting opportunity to analyze neuroimaging data at the single-subject level (9). Hence, the application of machine learning approaches that can facilitate the search for reliable neuroimaging biomarkers in both health and disease has been a highly discussed topic (5).

While most predictive analyses with neuroimaging data focus on dichotomous classification, there is an emerging trend in using regression-based machine learning approaches to reveal individual differences in disease severity or cognitive functioning from brain imaging data, i.e., the individualized prediction of human behaviors (3). Compared to binary classification, behavior prediction can be more challenging, since it considers the problem of quantitatively estimating the specific scores for a continuous behavioral measure over the whole range of the variable, instead of determining the group membership (10). Nevertheless, such applications can tell us more about the severity of symptom for a psychotic patient, the level of negative affect 
an individual tends to experience, or how well a participant can perform during a cognitive task. The biggest difference between predictive modeling and conventional correlational analysis is that predictive modeling generally employs a built-in cross-validation strategy to guard against the possibility of overfitting, which holds substantial promise for testing the generalizability of the identified biomarkers (11). The prediction of phenotypic measures requires dedicated design and techniques, recent reviews provide practical guidance on this topics $(11,12)$.

In this review, we will focus on approaches and cases specifically relevant to "cognitive biomarker" identification. We first outline various machine learning approaches and some key aspects on regression-based prediction, which aims to decode individual differences in a continuous behavioral phenotype from neuroimaging data. Next, we review studies on predictive modeling identified via a key word search in PubMed and Google Scholar over the past decade. Finally, challenges and future directions in the field of predictive modeling are discussed.
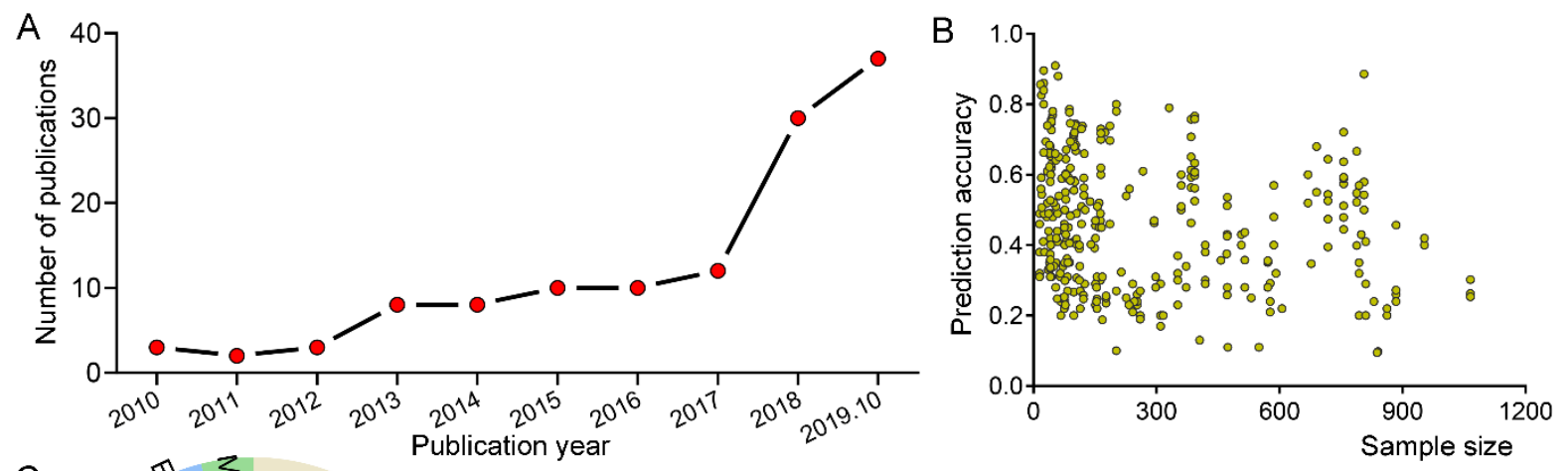

$$
\begin{aligned}
& r=-0.25 \\
& p=2.68 \times 10^{-6}
\end{aligned}
$$
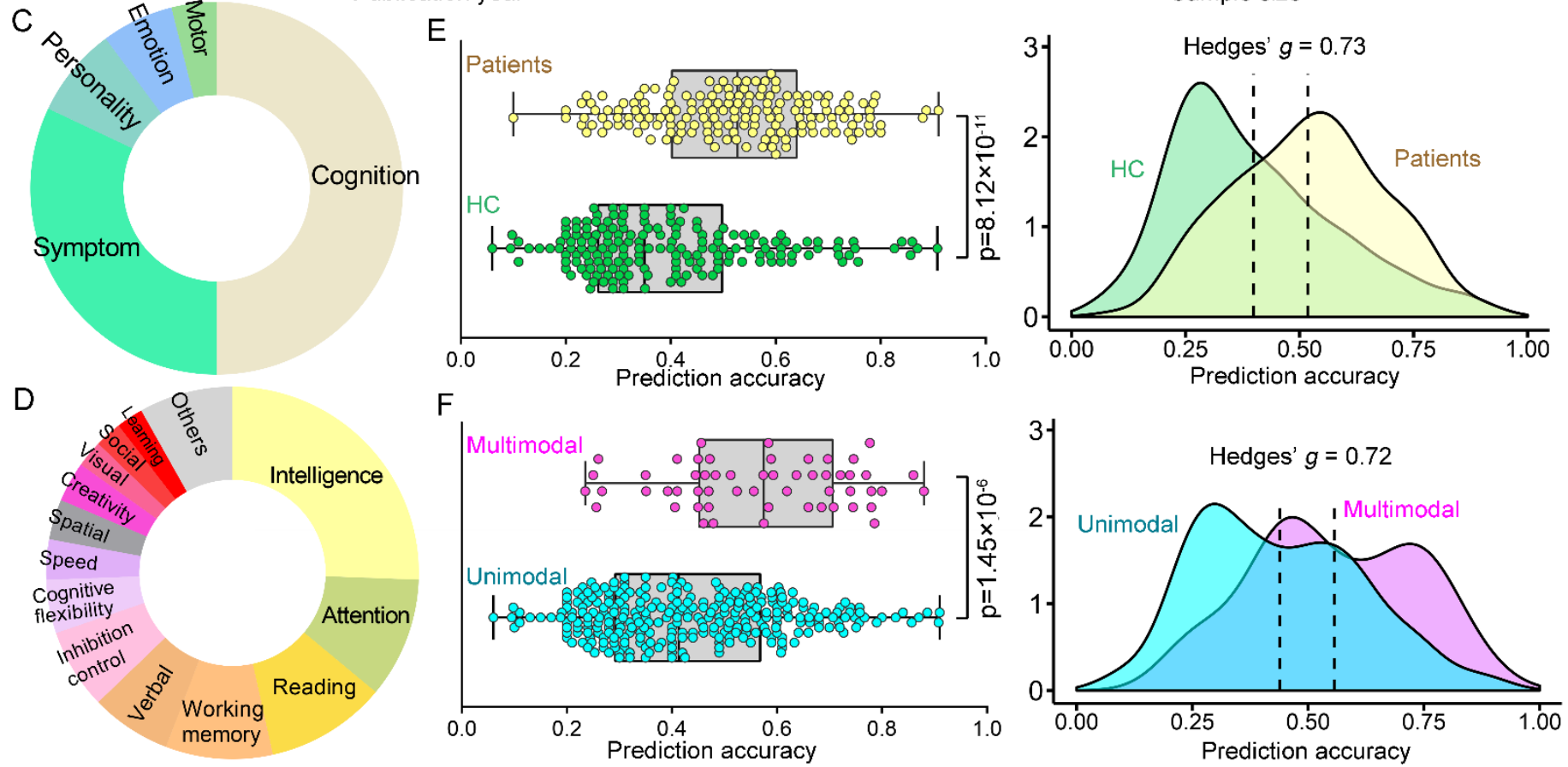

Figure 1. Visual summary of studies using regression-based machine learning approaches to predict continuous variables. (A) There is an obviously increasing trend in the number of papers published each year since 2010. (B) The overall prediction accuracy against the corresponding sample size used in the studies. (C) The type of behaviors of interest that are used as the target measures among all surveyed studies. (D) Cognitive 
bioRxiv preprint doi: https://doi.org/10.1101/2020.02.22.961136; this version posted February 25, 2020. The copyright holder for this preprint (which was not certified by peer review) is the author/funder, who has granted bioRxiv a license to display the preprint in perpetuity. It is made available under aCC-BY-NC-ND 4.0 International license.

metrics adopted in our surveyed studies. (E) Distribution of prediction accuracy for healthy subjects and patients with brain disorders shown as boxplot plot (left) and kernel density (right). (F) Distribution of prediction accuracy from studies using multimodal or unimodal data.

\section{Study search criteria and results}

Over the past few years, there has been increasing interest in using regression-based predictive modeling to determining cognition-related biomarkers. To summarize these studies, we performed a systematic review to include papers in English based on a search on PubMed and Google Scholar using search terms: "biomarker", "cogniti*”, "predict*”, "behavior*”, "regression”, "individual difference", "neuroimaging", "machine learning", and "cross validation", both in isolation and in combination. Searches were restricted to journal papers from January 2010 to October 2019. More than 500 papers were identified. We further reviewed the abstract and the full-text to restrict the papers to predictive studies that utilized regression-based machine learning approaches, employed cross-validation or external validation strategy to assess model generalizability, and reported the prediction accuracy using correlation coefficient. These criteria led to the inclusion of 122 papers on the topic of behavior prediction. Note that many studies performed prediction for more than one behavioral metric or several sub-dimensions of one cognitive scale. Overall, a total of 340 metric prediction accuracies were reported by all these 122 studies. Table $\mathbf{S 1}$ lists these studies in terms of employed imaging modality, behavioral measure of interest, sample size, adopted method, and prediction accuracy. We summarize these papers and illustrate some key aspects in Figure 1.

\section{Sample size vs Prediction accuracy}

There is an obviously increasing trend in the number of papers published each year (Figure 1A). Most of these studies have fewer than 200 participants, and a sample size of about 100 is the most common case (Figure 1B). In general, prediction accuracies exhibit a significantly negative correlation $(r=-0.25, p$ $=2.68 \times 10^{-6}$ ) with the sample sizes, suggesting that high prediction accuracies are more likely to be achieved on a small number of subjects. Previous studies suggest that a minimum of several hundred participants are required for predictive modeling to have adequate statistical power $(13,14)$. Small samples may not be representative of the general population, therefore, models built using small homogeneous datasets tend to mistakenly fit sample-specific idiosyncrasies (12). Failure to account for this optimism results in the fact that neuroimaging findings are hard to generalize in practice (15). Consequently, findings derived from small sample studies often yield low reliability and should be interpreted with great caution._By contrast, the use of large datasets increases the possibility of identifying robust and generalizable brain signatures due to a higher statistical power._In this regard, predictive models based on large samples should be given more priority and emphasis, even if these studies sometimes achieve relatively lower prediction accuracies. 
Importantly, the work from Sripada et al. is the largest predictive modeling study to date, which included 2013 subjects across 15 different sites from the Adolescent Brain Cognitive Development (ABCD) consortium (16) and predicted general cognitive ability using functional connectivity with leave-one-site-out crossvalidation. The robustness of results was validated in a series of control analyses including replication in splithalf analysis and in a low head-motion sample. In contrast to the leave-one-subject-out cross-validation, which has been criticized for inflated variance (12), the use of leave-one-site-out cross-validation guards against the possibility of detecting spurious brain-behavior relationships, improving our ability to identify brain signatures that will generalize.

Interestingly, a majority of the studies with large samples of subjects were performed on the publicly available data sharing initiatives, which encompass subjects spanning a range of developmental statuses and psychotic disorders. Promisingly, these data-sharing initiatives are making significant strides towards collecting large-scale neuroimaging datasets, driving the progress of brain-based biomarker discovery.

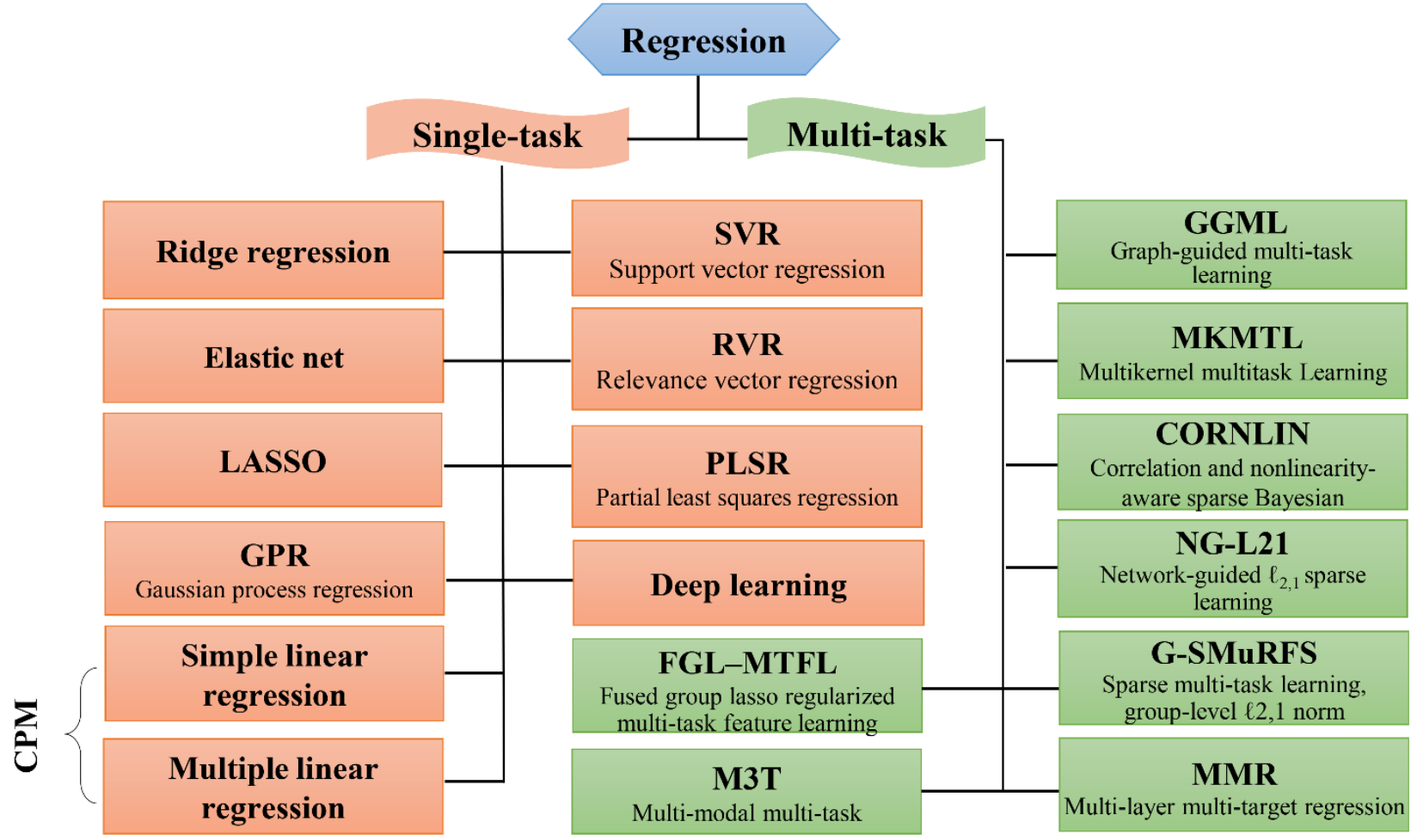

Figure 2. Summary of regression approaches used in our surveyed papers. Multi-task approaches jointly predict multiple clinical variables in a unified framework, while single-task methods only predict one type of cognitive score at one time. Most of the surveyed papers used linear models to reveal brain-behavior relationships. Connectome-based predictive modeling (CPM) is a recently developed data-driven approach that combines simple linear regression and feature selection together to predict individual differences in traits and behavior from connectivity data, and has been successfully employed for the prediction of multiple human behaviors.

\section{Overview of regression-based prediction models}

Figure 2 provides an overview of regression methods that are commonly adopted in our reviewed studies. 
These approaches can be divided into two main classes: single-task and multi-task. Multi-task approaches jointly predict multiple phenotypic variables in a unified framework by considering the dependence relationship among behavioral measures derived from a single cognitive test (17). Only a small number of studies performed multi-task predictions, consequently, we will not present a detailed discussion here.

Single-task methods predict only one type of phenotypic measure at one time. Such type of studies account for more than $90 \%$ of all surveyed papers. These methods primarily include the simple/multiple linear regression, relevance vector regression (RVR), linear support vector regression (SVR), ridge regression, LASSO, elastic net, partial least square regression (PLSR), and Gaussian process regression (GPR). Almost all of these methods belong to linear models, which are based on the hypothesis that there exists a linear relationship between brain imaging measurements and behavior scores. Although nonlinear approaches may be better suited for capturing complex brain-behavior relationships (10), the linear models could substantially reduce the possibility of overfitting and ensure good generalizability. Moreover, linear models have more interpretability, thereby allowing researchers to easily pinpoint the predictive brain regions and quantify their contribution by mapping them back to the original feature space and extracting their beta coefficients $(10,18)$. Here, we present some representative prediction models as follows.

Simple/multiple linear regression-Among all approaches, the simplest and most prevalent method for establishing brain-behavior relationship is simple/multiple linear regression (10). However, multiple linear regression requires the sample size to exceed feature dimension, and tends to overfit when the data is noisy. Given the high dimensional nature of neuroimaging data, these approaches are commonly accompanied by a feature selection step to obtain low-dimensionality representations (19). Typically, connectome-based predictive modeling $(\mathrm{CPM})$ is one of such approaches that combine simple linear regression and feature selection together to predict individual differences in traits and behavior from connectivity data $(3,10,20)$. Figure 3A shows a schematic summarizing the CPM pipeline. The CPM procedure has several advantages including straightforward interpretation, fast computation, and robust generalization, and has been successfully employed for the prediction of multiple human behaviors (20-23). Figure 3B-C show two example studies using CPM to predict individual differences in creativity and sustained attention.

LASSO_LASSO is a regularized regression method using an L1-norm penalty to reduce model complexity. LASSO shrinks most regressors' coefficient with low predictability to zero, and retains one arbitrary feature among the correlated ones (13). This means that some important features may be absent from the final model, which may lead to problems in feature interpretation.

Ridge regression-The ridge regression also employs the regularization technique to impose sparsity 
constraints. Ridge regression includes all features in the final prediction model and assigns similar coefficient values to the correlated features. Consequently, it has a good resilience to multicollinearity (24).

Elastic net-Elastic net can be seen as a combination of LASSO and ridge regression. It can not only achieve a sparse model through dropping features with low predictability but can retain groups of correlated features, thereby improving interpretability and stability (25).

SVR - To reduce model complexity, SVR works by placing constraints to ensure only a small number of observations (support vectors) are used. SVR works with the goal of constructing a regression line that fits the data within some chosen level of error (26). Due to an easy availability of implementation tools, SVR has been widely employed for behavior predictions.

RVR - RVR is a sparse kernel learning regression method based on Bayesian framework (27). Like SVR, only a relatively small number of samples (relevance vectors) are used to fit the model. RVR requires no extra computation for parameter tuning, therefore, it has a good generalizability and moderate computational cost.

PLSR - PLSR works by representing the high-dimensional features with a small number of latent components and then using these latent components to make predictions $(28,29)$. Consequently, PLSR does not need a feature selection step to reduce the feature dimension, and is particularly helpful in situations where the predictors are highly collinear and high dimensional.

\section{Study review of individualized prediction of human behavioral measures}

The regression-based machine learning models have been successfully applied in the prediction of several important behavioral aspects including cognition abilities, symptom severity, personality traits, emotion feelings and motor performance (Figure 1C). We now review these translational neuroimaging findings and present some example studies.

\section{Cognition}

As a core function of humans, cognition ubiquitously pervades one's daily life and plays a crucial role in determining how individuals understand, learn and communicate with the world. A majority of all reviewed papers focused on predicting cognition metrics. Such investigations attempt to unravel the secret of cognition processing by examining how the brain gives rise to cognition. General intelligence, attention and reading comprehension ability constitute the top three most studied cognitive metrics (Figure 1D).

Prediction of cognition has been most active in general intelligence (30-32). One recent study predicted the fluid intelligence scores in a sample of 515 subjects based on functional connectivity features, and confirmed the robustness of results by controlling for an array of potential factors including cross-validation method, head motion effect, global signal regression, and brain parcellation schemes. More importantly, the 
prediction models could be generalized to predict three intelligence-related measure in a large independent dataset ( $n=571$ ) (21). With respect to attention, Rosenberg et al. accomplished robust prediction of sustained attention using CPM in a sample of 25 healthy subjects (20), and more importantly, the identified neuromarkers were generalized to predict a series of attention-related measures like inhibition control, reading recall, and even a clinical measure for patients with attention-deficit/hyperactivity disorder (ADHD) in several independent data sets (33-36) (Figure 3C). Within a three-fold cross-validation framework, another study employed elastic net to decode individual differences in reading comprehension ability from grey matter volume for 507 healthy subjects, and further evaluated the generalizability in two external validation cohorts ( $n=372$ and $n=67)(37)$.

Apart from the aforementioned studies, predictive modelling has also been extended to achieve predictions for other cognitive metrics, including working memory (38-40), verbal learning (41), inhibition control $(42,43)$, processing speed $(44,45)$, cognitive flexibility $(42,46,47)$, creativity (48-50) and spatial orientation (51) using neuroimaging features of functional or structural connectivity, grey matter volume, cortical thickness and fractional anisotropy.

\section{Symptom severity}

In the clinical domain, most existing criteria to assess severity of brain disorders predominantly rely on subjective judgement of the patient symptoms and self-reported history. Machine learning-based predictive modeling has been utilized to decode symptom severity or cognition dysfunction from neuroimaging data. These models can establish the quantitative relationship between symptom scores and brain changes, which can further help us track the progress of neurological diseases and better understand the pathophysiology (52). Such models have been applied to patients with a spectrum of neurological or mental health disorders, such as schizophrenia $(53,54)$, autism spectrum disorder (ASD) $(25,55)$, depression (56-58), Alzheimer's disease (AD) (59-62), ADHD (22), Huntington's disease (26), obsessive-compulsive disorder (63, 64), and Parkinson's disease $(65,66)$. For example, based on cortical thickness measurements, Moradi et al. predicted the symptom severity scores for 156 subjects with ASD from four different sites (25). Another study presented a deep learning model for the prediction of clinical scores of disease severity for AD patients using structural MRI data (67). Within 10 rounds of 10-fold cross-validation, this model achieved high prediction accuracies across two independent large cohorts ( $n=669$ and $n=690)$.

Interestingly, models developed to predict behavioral measures for patients with brain disorders achieved significantly higher accuracies than models developed for health ( $\mathrm{p}=8.12 \times 10^{-11}$, Hedge's $g=0.73$, Figure 1E). A potential reason may be behavioral measures show small variations in the healthy controls instead of patients, 
which may be too low for the algorithms to pick up on predictive features. In contrast, many clinical measures are designed to pick up differences in patients. Notably, this result should be interpreted with caution, since these studies varied in a wide range of aspects, like the phenotypic measures, prediction approaches, sample size, and cross-validation schemes.

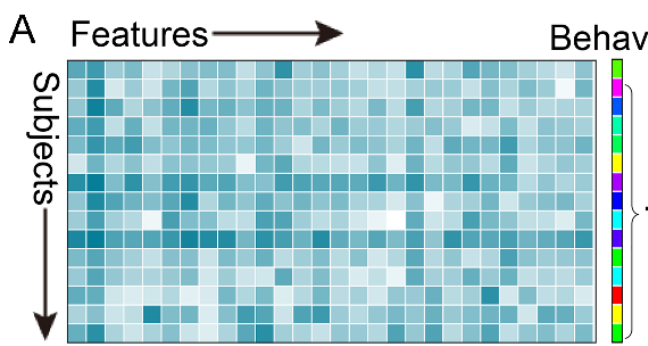

Feature matrix: $\mathrm{S} \times \mathrm{F}$
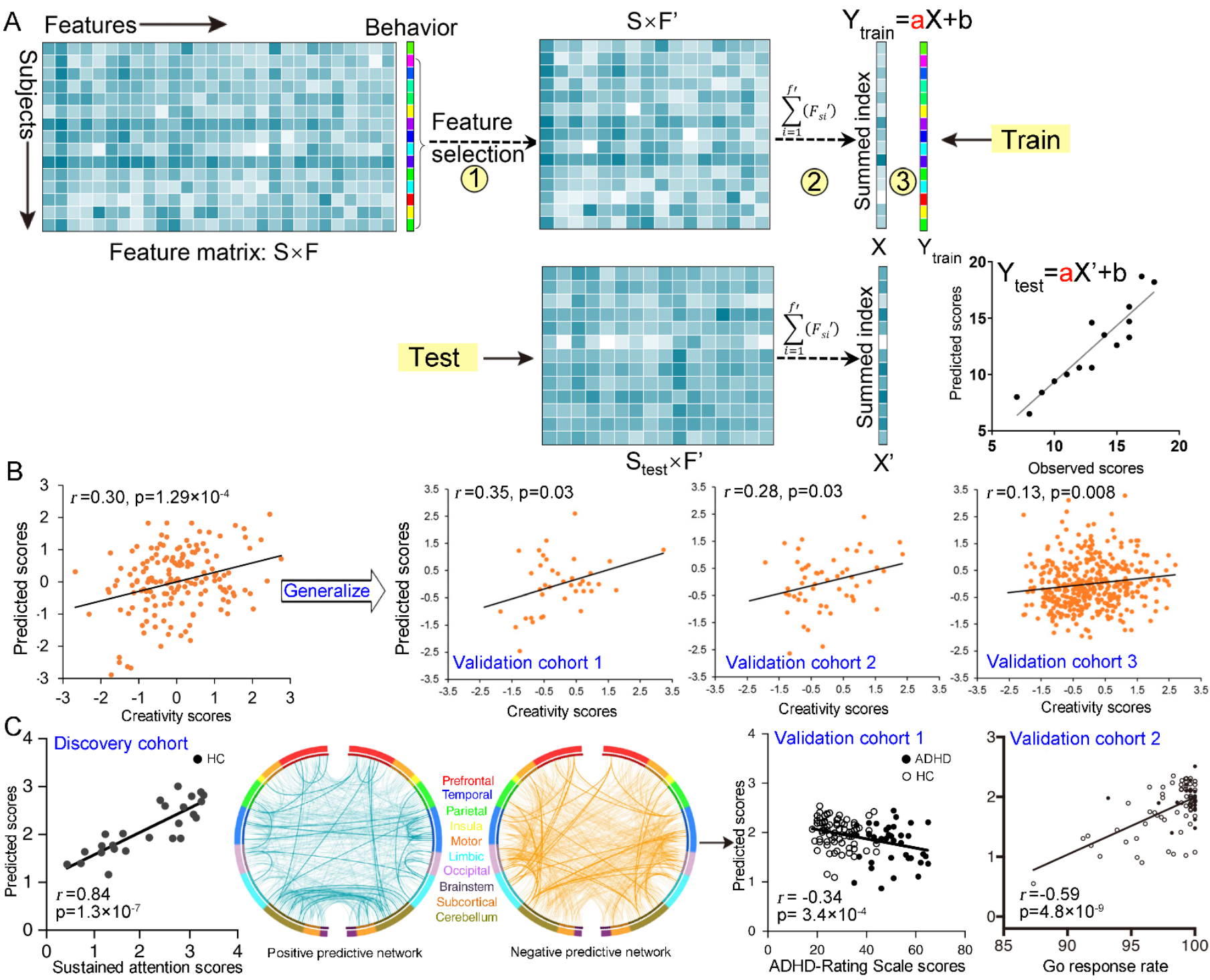

Figure 3. Overview of the connectome-based predictive modeling (CPM) framework and its applications in behavior prediction. (A) Overview of general analysis strategy for CPM procedure. Specifically, CPM is performed first by calculating the relevance of each connectivity feature to behavioral measure of interest across subjects and retaining the most significantly correlated ones under a predefined threshold. And then, a single aggregate metric named 'network strength' is computed by summing strength of the retained connectivity features. Afterwards, the summary statistics and behavioral scores are submitted to a simple linear regression model. By placing the procedure within a cross-validation framework, accurate estimations of behavioral scores can be obtained. (B) Beaty et al. accomplished robust prediction of individual creative ability using FCs acquired from 163 participants engaged in a classic divergent thinking task, and assessed the generalizability in three external cohorts $(n=39,54$, and 405). (C) Rosenberg et al. accomplished robust prediction of sustained attention using CPM in a sample of 25 healthy subjects, and the identified neuromarkers were generalized to predict a clinical measure for patients with ADHD (validation cohort 1, $n=113$ ) and individuals' go response rate in a stop-signal task (validation cohort $2, n=83$ ). (Adapted from ref. $(48)$, and $(20,36))$. 
bioRxiv preprint doi: https://doi.org/10.1101/2020.02.22.961136; this version posted February 25, 2020. The copyright holder for this preprint (which was not certified by peer review) is the author/funder, who has granted bioRxiv a license to display the preprint in perpetuity. It is made available under aCC-BY-NC-ND 4.0 International license.

\section{Personality}

Personality is a relatively stable trait consisting of a collection of behaviors, thoughts, cognitions, and emotional characteristics that evolve from biological and environmental factors (68). Personality represents an individual's disposition that influences long-term behavioral style (24). Among all personality dimensions, traits measured using the Five-Factor Inventory, which encompasses five broad dimensions of extraversion, neuroticism, agreeableness, conscientiousness and openness to experience, have been most widely investigated. For example, within a leave-one-family-out cross-validation, Dubois et al. predicted the scores of openness and a personality factor generated from the principal component analysis using elastic net in a large sample of 884 adults (24). Another study, based on nine meta-analytically derived functional networks and RVR, demonstrated the predictability of extraversion, neuroticism, agreeableness and openness within a 10 -fold cross-validation in a sample of 420 subjects, and assessed the generalizability of findings in a replication sample of 310 subjects (69). Moreover, this study suggested that the functional networks linked to each personality dimension were gender-specific. Other personality traits being investigated primarily include temperament $(70,71)$, narcissism (72), and dispositional worry (27).

\section{Emotion}

Only a limited number of studies have attempted to identify biomarkers for emotion related behaviors using predictive modeling, which have largely deepened our understanding of the underlying neurobiological substrates. These emotion measures primarily include individuals' feeling of loneness (73), anxiety (74-76), fear of pain (77), intensity of interoception (78), as well as constructs associated with social relationships like propensity to trust (79) and deception (80).

Apart from the above mentioned phenotypic aspects, there are also some other behavioral domains being investigated $(81,82)$. A remarkable example is the study that identified an fMRI-based brain signature of pain intensity, and showed its generalizability in multiple independent datasets (81). Due to word limits, we will not describe these studies in detail.

\section{Challenges and future directions}

The studies surveyed above highlight the potential of using regression-based predictive modeling to identify neuromarkers and characterize the neurodiversity of the human brain in both health and disease. Despite such success, some issues should be mentioned and lots of work remains to be done.

\section{Prediction using Multimodal data}

Recently, collecting multimodal brain data from the same subject has become a common practice (41, $83,84)$. Integrating multimodal data could effectively capitalize on the strength of each imaging modality and 
provide a comprehensive view into the brain (85). As such, in the surveyed papers, studies using multimodal data to predict individuals' behaviors achieved significantly higher accuracies than those using unimodal data $\left(\mathrm{p}=1.45 \times 10^{-6}\right.$, Hedge's $g=0.72$, Figure 1F). A recent study predicted the intelligence quotient scores using resting-state functional connectivity and grey matter cortical thickness, and found that integrating multimodal data improved prediction accuracy (86). More importantly, this study suggested that these two types of neuroimaging features provided unique evidence of the neurobiological correlates of intelligence from distinct perspectives (Figure 4A).

However, the multimodal prediction was primarily achieved by simply concatenating brain features from different modalities horizontally into a single, combined feature space and submitting them into a regression model, thereby not allowing for a full use of the joint information among modalities. Multimodal fusion can uncover cross-information beyond what can be detected by each single modality (85). For example, Qi et al. proposed a supervised multimodal fusion approach named MCCAR+jICA, which can detect co-varying multimodal imaging patterns (84). In a three-way fusion simulation, the method identified four multimodal brain signatures located in the salience network, central executive network and default mode network, which were successfully used to predict multi-domain cognition in two independent cohorts (87) (Figure 4B). The use of brain signatures derived from multimodal fusion approaches to predict cognition can promote the identification of neuromarkers and inform our understanding of how functionally and structurally connected brain systems contributed to cognitive function.

\section{Validating biomarkers in independent data sets}

Many existing studies detecting neuromarkers predominately focus on revealing new findings for a cascade of novel behavioral measures. However, additional effort should also be devoted to testing the generalizability and reproducibility of the constructed predictive models (88), especially for those developed on dataset with an insufficient sample size. Considering a potentially inflated false-positive rate due to the low statistical power, concerns have been raised about the reliability and reproducibility of neuroimaging findings $(89,90)$. However, very few studies have tested brain models on external validation/replication datasets due to generalization failure or lack of additional independent data. One potential solution to this issue is to encourage individual projects to share their neuroimaging data so that researchers can leverage the publicly available data. The shared big-data sources can serve as benchmark data sets, allowing people to establish reproducible imaging-based biomarkers (91). Moreover, the neuroimaging community should raise awareness that replication and validation are as important as novelty (89). 
In practice, assessments of behavioral measures can be based either on subjective report or on objective behavioral recordings. The self-reported measures are usually derived from subjects' ratings of a conventional scale according to their personal experience or judgement on a specific item. This means that the measured scores rely largely on individuals' subjective appraisal of the trait. Consequently, such measures are likely to be influenced by unknown factors and are not stable. In contrast, behavioral measures assessed using participants' performance in a task where participants are incited to reach a high score (92), objectively reflect ones' inherent traits and relate to more reliability, placing an upper limit on the maximum detectable effect size (93). Some studies have reported that objective variables can be better predicted than subjective ratings $(94,95)$. In addition, it has also been suggested that cognitive tasks amplified trait-relevant individual differences in functional connectivity patterns and integrating different tasks into a single predictive model did improve cognition prediction $(21,96,97)$. Therefore, we encourage future studies to use task performance to measure individuals' behavioral scores and combining multiple task connectomes to investigate brainbehavior relationships.

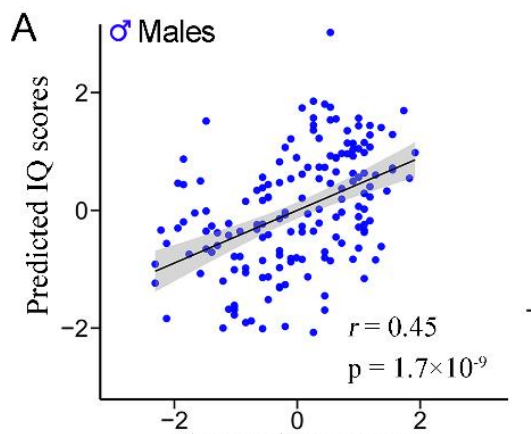
Observed IQ scores
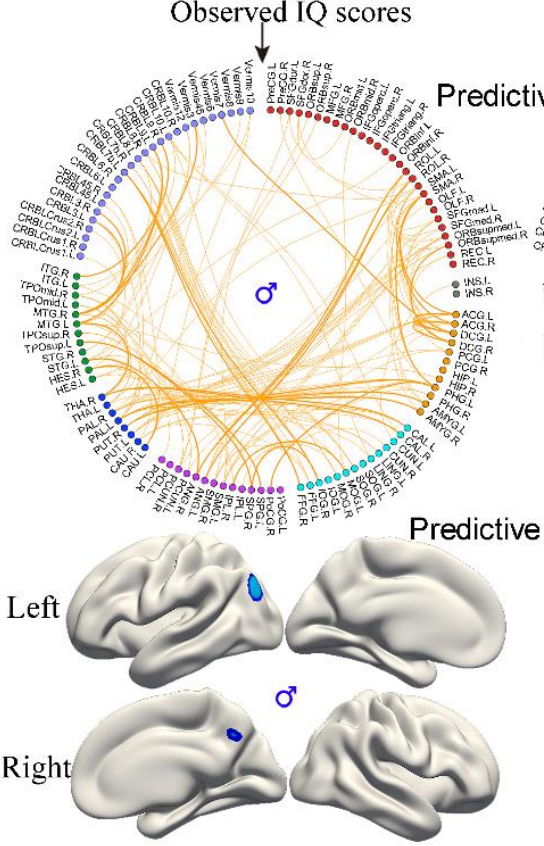
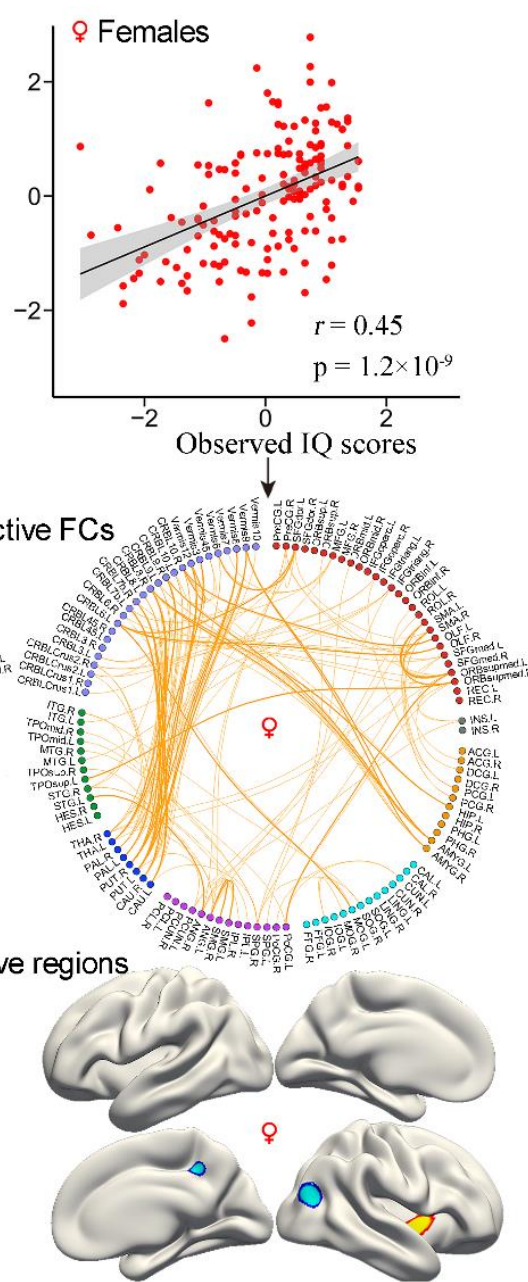

B

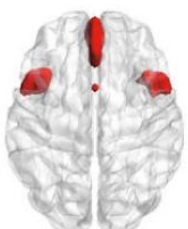

SAN-SMRI
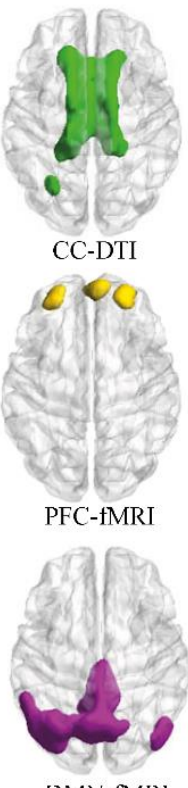

DMN-fMRI
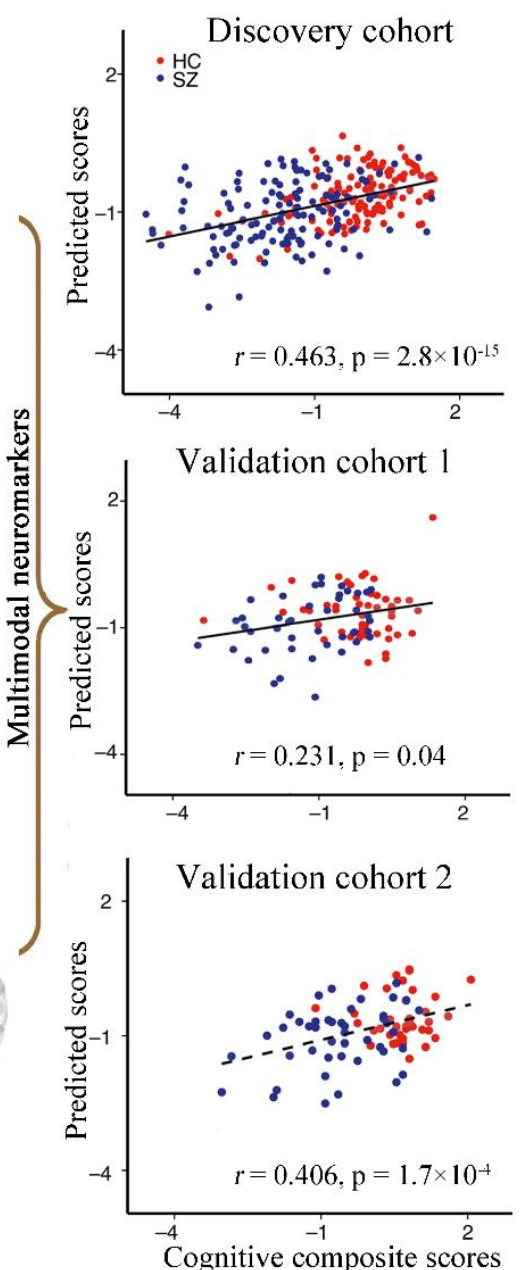

Figure 4. Using multimodal data to predict cognition promotes the biomarker identification. (A) Jiang et al. achieved an improved prediction performance of intelligence scores by integrating FCs and cortical thickness. More importantly, the study suggested that these two types of neuroimaging features provided unique evidence of the neurobiological correlates of intelligence from distinct perspective. Specifically, prediction with cortical thickness explored more gender difference in the lateralization of predictive brain regions, while prediction 
bioRxiv preprint doi: https://doi.org/10.1101/2020.02.22.961136; this version posted February 25, 2020. The copyright holder for this preprint (which was not certified by peer review) is the author/funder, who has granted bioRxiv a license to display the preprint in perpetuity. It is made available under aCC-BY-NC-ND 4.0 International license.

with FCs detected more gender difference in the specification of contributing functional networks. (B) Sui et al. predicted the cognitive composite scores for subjects from three independent cohorts based on neuromarkers derived from a supervised multimodal fusion approach (Adapted from ref. (86), and (87)).

\section{Applying deep learning methods}

Recent studies have started to use deep learning methods to predict individual differences in behavioral phenotypes and brain maturity. Based on neural networks, deep learning serves as an extension of traditional machine learning methods (98). Deep learning can automatically learn a higher level of abstract representation through the application of consecutive nonlinear transformations to raw input data in "hidden" neural network layers, making this approach ideally suited to detecting complex, scattered and subtle brain patterns (99). One advantage of deep learning is that it can remove the reliance on time-consuming pre-processing and prior feature selection, avoiding the related model-dependent decisions (100). However, compared to other fields, the application of deep learning methods to predictive modeling in neuroimaging is relatively modest. There are two main reasons, one being the lack of interpretability and the other being the need for extensive amounts of data. Specifically, one study suggested that, lacking large quantity of data, deep learning models may not outperform classical machine learning approaches in cognition predictions (101). Therefore, many efforts are required to overcome these drawbacks before the full potential of deep learning in behavior prediction is explored.

\section{Developing longitudinally predictive models}

The vast majority of predictive studies have focused on cross-sectional predictions, that is, the MRI data and the behavioral measure of interest are acquired at the same time or within a short time interval. Although there is evidence showing that certain brain imaging features are unique and stable over months to years (102), to what degree these features will show predictability for behavioral phenotypes consistently across time still remains largely unexplored. To benefit educational or healthy practices, longitudinal predictive models should be developed to predict long-term outcomes using baseline neuroimaging data $(2,11)$. Biomarkers derived from such applications commonly relate to more biological significance and clinical utility, since individuals can benefit from early invention and treatment.

\section{Conclusions}

In this study, we reviewed recent advances in the field of predictive modeling that employs regressionbased machine learning approaches to decode individual differences in behavioral phenotypes from brain imaging data. Although this burgeoning field is still immature with many issues being solved and not quite ready for integration into clinical use, we are optimistic about the development of brain models that can be eventually integrated into clinical applications as this area matures. 
bioRxiv preprint doi: https://doi org/10.1101/2020.02.22.961136; this version posted February 25, 2020. The copyright holder for this preprint (which was not certified by peer review) is the author/funder, who has granted bioRxiv a license to display the preprint in perpetuity. It is made available under aCC-BY-NC-ND 4.0 International license.

\section{Acknowledgments}

This work is supported in part by the National Institute of Health (1R01MH117107, R01EB020407, P20GM103472, P30GM122734) and the National Science Foundation (1539067), the China Natural Science Foundation (61773380), the Strategic Priority Research Program of the Chinese Academy of Sciences (No. XDB32040100), Brain Science and Brain-inspired Technology Plan of Beijing City (Z181100001518005),

The authors declare no biomedical financial interests or potential conflicts of interest.

\section{References}

1. Kyle S, Tavel J (2010): What are Biomarkers? Current Opinion in HIV and AIDS. 5:463-466.

2. Gabrieli JD, Ghosh SS, Whitfield-Gabrieli S (2015): Prediction as a humanitarian and pragmatic contribution from human cognitive neuroscience. Neuron. 85:11-26.

3. Finn ES, Shen X, Scheinost D, Rosenberg MD, Huang J, Chun MM, et al. (2015): Functional connectome fingerprinting: identifying individuals using patterns of brain connectivity. Nat Neurosci. 18:1664-1671.

4. Arbabshirani MR, Plis S, Sui J, Calhoun VD (2016): Single subject prediction of brain disorders in neuroimaging: Promises and pitfalls. Neuroimage.

5. Gao S, Calhoun VD, Sui J (2018): Machine learning in major depression: From classification to treatment outcome prediction. CNS neuroscience \& therapeutics. 24:1037-1052.

6. Yarkoni T, Westfall J (2017): Choosing Prediction Over Explanation in Psychology: Lessons From Machine Learning. Perspect Psychol Sci. 12:1100-1122.

7. Woo CW, Chang LJ, Lindquist MA, Wager TD (2017): Building better biomarkers: brain models in translational neuroimaging. Nat Neurosci. 20:365-377.

8. Kambeitz J, Kambeitz-Ilankovic L, Leucht S, Wood S, Davatzikos C, Malchow B, et al. (2015): Detecting neuroimaging biomarkers for schizophrenia: a meta-analysis of multivariate pattern recognition studies. Neuropsychopharmacology. 40:1742-1751.

9. Osuch E, Gao S, Wammes M, Théberge J, Williamson P, Neufeld R, et al. (2018): Complexity in mood disorder diagnosis: fMRI connectivity networks predicted medication - class of response in complex patients. Acta psychiatrica Scandinavica. 138:472-482.

10. Shen X, Finn ES, Scheinost D, Rosenberg MD, Chun MM, Papademetris X, et al. (2017): Using connectome-based predictive modeling to predict individual behavior from brain connectivity. Nature Protocols. 12:506-518.

11. Rosenberg MD, Casey BJ, Holmes AJ (2018): Prediction complements explanation in understanding the developing brain. Nature communications. 9:589.

12. Scheinost D, Noble S, Horien C, Greene AS, Lake EM, Salehi M, et al. (2019): Ten simple rules for predictive modeling of individual differences in neuroimaging. Neuroimage. 193:35-45.

13. Cui Z, Gong G (2018): The effect of machine learning regression algorithms and sample size on individualized behavioral prediction with functional connectivity features. Neuroimage. 178:622-637.

14. Luedtke A, Sadikova E, Kessler RC (2019): Sample Size Requirements for Multivariate Models to Predict Between-Patient Differences in Best Treatments of Major Depressive Disorder. Clinical Psychological Science. 7:445-461.

15. Whelan R, Garavan H (2014): When optimism hurts: inflated predictions in psychiatric neuroimaging. Biological psychiatry. 75:746-748.

16. Sripada C, Rutherford S, Angstadt M, Thompson WK, Luciana M, Weigard A, et al. (2019): Prediction of neurocognition in youth from resting state fMRI. Molecular psychiatry. 
bioRxiv preprint doi: https://doi.org/10.1101/2020.02.22.961136; this version posted February 25, 2020. The copyright holder for this preprint (which was not certified by peer review) is the author/funder, who has granted bioRxiv a license to display the preprint in perpetuity. It is made available under aCC-BY-NC-ND 4.0 International license.

17. Yan J, Huang H, Risacher SL, Kim S, Inlow M, Moore JH, et al. (2013): Network-Guided Sparse Learning for Predicting Cognitive Outcomes from MRI Measures. Multimodal brain image analysis : third International Workshop, MBIA 2013, held in conjunction with MICCAI 2013, Nagoya, Japan, September 22, 2013 : proceedings / Li Shen, Tianming Liu, Pew-Thian Yap, Heng Huang, Dingg. 8159:202-210.

18. Haufe S, Meinecke F, Gorgen K, Dahne S, Haynes JD, Blankertz B, et al. (2014): On the interpretation of weight vectors of linear models in multivariate neuroimaging. Neuroimage. 87:96-110.

19. Bermingham ML, Pong-Wong R, Spiliopoulou A, Hayward C, Rudan I, Campbell H, et al. (2015): Application of high-dimensional feature selection: evaluation for genomic prediction in man. Scientific reports. 5.

20. Rosenberg MD, Finn ES, Scheinost D, Papademetris X, Shen X, Constable RT, et al. (2016): A neuromarker of sustained attention from whole-brain functional connectivity. Nat Neurosci. 19:165-171.

21. Greene AS, Gao S, Scheinost D, Constable RT (2018): Task-induced brain state manipulation improves prediction of individual traits. Nature communications. 9:2807.

22. Lake EMR, Finn ES, Noble SM, Vanderwal T, Shen X, Rosenberg MD, et al. (2019): The Functional Brain Organization of an Individual Allows Prediction of Measures of Social Abilities Transdiagnostically in Autism and Attention-Deficit/Hyperactivity Disorder. Biological psychiatry. 86:315-326.

23. Hsu WT, Rosenberg MD, Scheinost D, Constable RT, Chun MM (2018): Resting-state functional connectivity predicts neuroticism and extraversion in novel individuals. Social cognitive and affective neuroscience. 13:224-232.

24. Dubois J, Galdi P, Han Y, Paul LK, Adolphs R (2018): Resting-state functional brain connectivity best predicts the personality dimension of openness to experience. Personal Neurosci. 1.

25. Moradi E, Khundrakpam B, Lewis JD, Evans AC, Tohka J (2017): Predicting symptom severity in autism spectrum disorder based on cortical thickness measures in agglomerative data. Neuroimage. 144:128-141.

26. Rizk-Jackson A, Stoffers D, Sheldon S, Kuperman J, Dale A, Goldstein J, et al. (2011): Evaluating imaging biomarkers for neurodegeneration in pre-symptomatic Huntington's disease using machine learning techniques. NeuroImage. 56:788-796.

27. Feng C, Cui Z, Cheng D, Xu R, Gu R (2018): Individualized prediction of dispositional worry using white matter connectivity. Psychol Med.1-10.

28. Yoo K, Rosenberg MD, Hsu WT, Zhang S, Li CR, Scheinost D, et al. (2017): Connectome-based predictive modeling of attention: Comparing different functional connectivity features and prediction methods across datasets. Neuroimage. 167:11-22.

29. Chen C, Cao X, Tian L (2019): Partial Least Squares Regression Performs Well in MRI-Based Individualized Estimations. Front Neurosci. 13:1282.

30. Dubois J, Galdi P, Paul LK, Adolphs R (2018): A distributed brain network predicts general intelligence from resting-state human neuroimaging data. Philosophical transactions of the Royal Society of London Series B, Biological sciences. 373.

31. Jiang R, Calhoun VD, Fan L, Zuo N, Jung R, Qi S, et al. (2019): Gender Differences in Connectomebased Predictions of Individualized Intelligence Quotient and Sub-domain Scores. Cerebral Cortex.

32. Ferguson MA, Anderson JS, Spreng RN (2017): Fluid and flexible minds: Intelligence reflects synchrony in the brain's intrinsic network architecture. Netw Neurosci. 1:192-207.

33. Fountain-Zaragoza S, Samimy S, Rosenberg MD, Prakash RS (2019): Connectome-based models predict attentional control in aging adults. Neuroimage. 186:1-13.

34. Rosenberg MD, Hsu WT, Scheinost D, Todd Constable R, Chun MM (2018): Connectome-based Models Predict Separable Components of Attention in Novel Individuals. J Cogn Neurosci. 30:160-173.

35. Jangraw DC, Gonzalez-Castillo J, Handwerker DA, Ghane M, Rosenberg MD, Panwar P, et al. (2018): A functional connectivity-based neuromarker of sustained attention generalizes to predict recall in a reading task. 
bioRxiv preprint doi: https://doi.org/10.1101/2020.02.22.961136; this version posted February 25, 2020. The copyright holder for this preprint (which was not certified by peer review) is the author/funder, who has granted bioRxiv a license to display the preprint in perpetuity. It is made available under aCC-BY-NC-ND 4.0 International license.

Neuroimage. 166:99-109.

36. Rosenberg MD, Zhang S, Hsu WT, Scheinost D, Finn ES, Shen X, et al. (2016): Methylphenidate Modulates Functional Network Connectivity to Enhance Attention. J Neurosci. 36:9547-9557.

37. Cui Z, Su M, Li L, Shu H, Gong G (2017): Individualized Prediction of Reading Comprehension Ability Using Gray Matter Volume. Cereb Cortex.1-17.

38. Yamashita M, Yoshihara Y, Hashimoto R, Yahata N, Ichikawa N, Sakai Y, et al. (2018): A prediction model of working memory across health and psychiatric disease using whole-brain functional connectivity. eLife. 7. 39. Bertolero MA, Yeo BTT, Bassett DS, D'Esposito M (2018): A mechanistic model of connector hubs, modularity and cognition. Nat Hum Behav. 2:765-777.

40. Yamashita M, Kawato M, Imamizu H (2015): Predicting learning plateau of working memory from whole-brain intrinsic network connectivity patterns. Scientific reports. 5:7622.

41. Qi S, Sui J, Chen J, Liu J, Jiang R, Silva R, et al. (2019): Parallel group ICA+ICA: Joint estimation of linked functional network variability and structural covariation with application to schizophrenia. Hum Brain Mapp.

42. Liu J, Liao X, Xia M, He Y (2018): Chronnectome fingerprinting: Identifying individuals and predicting higher cognitive functions using dynamic brain connectivity patterns. Hum Brain Mapp. 39:902-915.

43. He N, Rolls ET, Zhao W, Guo S (2019): Predicting human inhibitory control from brain structural MRI. Brain imaging and behavior.

44. Kuceyeski A, Monohan E, Morris E, Fujimoto K, Vargas W, Gauthier SA (2018): Baseline biomarkers of connectome disruption and atrophy predict future processing speed in early multiple sclerosis. NeuroImage Clinical. 19:417-424.

45. Sripada C, Angstadt M, Rutherford S, Kessler D, Kim Y, Yee M, et al. (2019): Basic Units of InterIndividual Variation in Resting State Connectomes. Scientific reports. 9:1900.

46. Zhu J, Zhu D-m, Zhang C, Wang Y, Yang Y, Yu Y (2019): Quantitative prediction of individual cognitive flexibility using structural MRI. Brain imaging and behavior. 13:781-788.

47. Chen OY, Cao H, Reinen JM, Qian T, Gou J, Phan H, et al. (2019): Resting-state brain information flow predicts cognitive flexibility in humans. Scientific reports. 9:3879.

48. Beaty RE, Kenett YN, Christensen AP, Rosenberg MD, Benedek M, Chen Q, et al. (2018): Robust prediction of individual creative ability from brain functional connectivity. Proc Natl Acad Sci US A.

49. Liu Z, Zhang J, Xie X, Rolls ET, Sun J, Zhang K, et al. (2018): Neural and genetic determinants of creativity. NeuroImage. 174:164-176.

50. Chen Q, Beaty RE, Cui Z, Sun J, He H, Zhuang K, et al. (2019): Brain hemispheric involvement in visuospatial and verbal divergent thinking. Neuroimage. 202:116065.

51. Powell MA, Garcia JO, Yeh FC, Vettel JM, Verstynen T (2018): Local connectome phenotypes predict social, health, and cognitive factors. Netw Neurosci. 2:86-105.

52. Cheng B, Zhang D, Chen S, Kaufer DI, Shen D, Alzheimer's Disease Neuroimaging I (2013): Semisupervised multimodal relevance vector regression improves cognitive performance estimation from imaging and biological biomarkers. Neuroinformatics. 11:339-353.

53. Meng X, Jiang R, Lin D, Bustillo J, Jones T, Chen J, et al. (2017): Predicting individualized clinical measures by a generalized prediction framework and multimodal fusion of MRI data. Neuroimage. 145:218229.

54. Wang D, Li M, Wang M, Schoeppe F, Ren J, Chen H, et al. (2018): Individual-specific functional connectivity markers track dimensional and categorical features of psychotic illness. Molecular psychiatry.

55. Yahata N, Morimoto J, Hashimoto R, Lisi G, Shibata K, Kawakubo Y, et al. (2016): A small number of abnormal brain connections predicts adult autism spectrum disorder. Nature communications. 7:11254.

56. Mwangi B, Matthews K, Steele JD (2012): Prediction of illness severity in patients with major depression 
bioRxiv preprint doi: https://doi.org/10.1101/2020.02.22.961136; this version posted February 25, 2020. The copyright holder for this preprint (which was not certified by peer review) is the author/funder, who has granted bioRxiv a license to display the preprint in perpetuity. It is made available under aCC-BY-NC-ND 4.0 International license.

using structural MR brain scans. Journal of Magnetic Resonance Imaging. 35:64-71.

57. Yoshida K, Shimizu Y, Yoshimoto J, Takamura M, Okada G, Okamoto Y, et al. (2017): Prediction of clinical depression scores and detection of changes in whole-brain using resting-state functional MRI data with partial least squares regression. PloS one. 12:e179638.

58. Johnston BA, Steele JD, Tolomeo S, Christmas D, Matthews K (2015): Structural MRI-Based Predictions in Patients with Treatment-Refractory Depression (TRD). PloS one. 10:e132958.

59. Lin Q, Rosenberg MD, Yoo K, Hsu TW, O'Connell TP, Chun MM (2018): Resting-State Functional Connectivity Predicts Cognitive Impairment Related to Alzheimer's Disease. Frontiers in aging neuroscience. $10: 94$.

60. Moradi E, Hallikainen I, Hanninen T, Tohka J, Alzheimer's Disease Neuroimaging I (2017): Rey's Auditory Verbal Learning Test scores can be predicted from whole brain MRI in Alzheimer's disease. NeuroImage Clinical. 13:415-427.

61. Stonnington CM, Chu C, Kloppel S, Jack CR, Jr., Ashburner J, Frackowiak RS, et al. (2010): Predicting clinical scores from magnetic resonance scans in Alzheimer's disease. Neuroimage. 51:1405-1413.

62. Liu X, Cao P, Wang J, Kong J, Zhao D (2019): Fused Group Lasso Regularized Multi-Task Feature Learning and Its Application to the Cognitive Performance Prediction of Alzheimer's Disease. Neuroinformatics. 17:271-294.

63. Hoexter MQ, Miguel EC, Diniz JB, Shavitt RG, Busatto GF, Sato JR (2013): Predicting obsessivecompulsive disorder severity combining neuroimaging and machine learning methods. Journal of affective disorders. 150:1213-1216.

64. Brennan BP, Wang D, Li M, Perriello C, Ren J, Elias JA, et al. (2019): Use of an Individual-Level Approach to Identify Cortical Connectivity Biomarkers in Obsessive-Compulsive Disorder. Biol Psychiatry Cogn Neurosci Neuroimaging. 4:27-38.

65. Li X, Xiong Y, Liu S, Zhou R, Hu Z, Tong Y, et al. (2019): Predicting the Post-therapy Severity Level (UPDRS-III) of Patients With Parkinson's Disease After Drug Therapy by Using the Dynamic Connectivity Efficiency of fMRI. Frontiers in Neurology. 10.

66. Hou Y, Luo C, Yang J, Ou R, Song W, Wei Q, et al. (2016): Prediction of individual clinical scores in patients with Parkinson's disease using resting-state functional magnetic resonance imaging. J Neurol Sci. 366:27-32.

67. Bhagwat N, Pipitone J, Voineskos AN, Chakravarty MM, Alzheimer's Disease Neuroimaging I (2019): An artificial neural network model for clinical score prediction in Alzheimer disease using structural neuroimaging measures. Journal of psychiatry \& neuroscience : JPN. 44:246-260.

68. Corr PJ, Matthews G (2009): The Cambridge handbook of personality psychology. Cambridge University Press Cambridge.

69. Nostro AD, Müller VI, Varikuti DP, Pläschke RN, Hoffstaedter F, Langner R, et al. (2018): Predicting personality from network-based resting-state functional connectivity. Brain Structure and Function.

70. Wei L, Guo N, Baeken C, Bi M, Wang X, Qiu J, et al. (2019): Grey Matter Volumes in the Executive Attention System Predict Individual Differences in Effortful Control in Young Adults. Brain Topogr. 32:111117.

71. Jiang R, Calhoun VD, Zuo N, Lin D, Li J, Fan L, et al. (2018): Connectome-based individualized prediction of temperament trait scores. Neuroimage. 183:366-374.

72. Feng C, Yuan J, Geng H, Gu R, Zhou H, Wu X, et al. (2018): Individualized prediction of trait narcissism from whole-brain resting-state functional connectivity. Hum Brain Mapp.

73. Feng C, Wang L, Li T, Xu P (2019): Connectome-based individualized prediction of loneliness. Social cognitive and affective neuroscience. 14:353-365.

74. Boeke EA, Holmes AJ, Phelps EA (2019): Towards robust anxiety biomarkers: A machine learning 
bioRxiv preprint doi: https://doi.org/10.1101/2020.02.22.961136; this version posted February 25, 2020. The copyright holder for this preprint (which was not certified by peer review) is the author/funder, who has granted bioRxiv a license to display the preprint in perpetuity. It is made available under aCC-BY-NC-ND 4.0 International license.

approach in a large-scale sample. Biological Psychiatry: Cognitive Neuroscience and Neuroimaging.

75. Greening SG, Mitchell DG (2015): A network of amygdala connections predict individual differences in trait anxiety. Hum Brain Mapp. 36:4819-4830.

76. Qin S, Young CB, Duan X, Chen T, Supekar K, Menon V (2014): Amygdala subregional structure and intrinsic functional connectivity predicts individual differences in anxiety during early childhood. Biological psychiatry. 75:892-900.

77. Wang X, Baeken C, Fang M, Qiu J, Chen H, Wu GR (2018): Predicting trait-like individual differences in fear of pain in the healthy state using gray matter volume. Brain imaging and behavior.

78. Wu X, Shi L, Wei D, Qiu J (2019): Brain connection pattern under interoceptive attention state predict interoceptive intensity and subjective anxiety feeling. Hum Brain Mapp. 40:1760-1773.

79. Lu X, Li T, Xia Z, Zhu R, Wang L, Luo YJ, et al. (2019): Connectome-based model predicts individual differences in propensity to trust. Hum Brain Mapp. 40:1942-1954.

80. Tang H, Lu X, Cui Z, Feng C, Lin Q, Cui X, et al. (2018): Resting-state Functional Connectivity and Deception: Exploring Individualized Deceptive Propensity by Machine Learning. Neuroscience. 395:101-112. 81. Wager TD, Atlas LY, Lindquist MA, Roy M, Woo CW, Kross E (2013): An fMRI-based neurologic signature of physical pain. $N$ Engl J Med. 368:1388-1397.

82. Yip SW, Scheinost D, Potenza MN, Carroll KM (2019): Connectome-Based Prediction of Cocaine Abstinence. American Journal of Psychiatry. 176:156-164.

83. Sui J, Pearlson GD, Du Y, Yu Q, Jones TR, Chen J, et al. (2015): In search of multimodal neuroimaging biomarkers of cognitive deficits in schizophrenia. Biological psychiatry. 78:794-804.

84. Qi S, Yang X, Zhao L, Calhoun VD, Perrone-Bizzozero N, Liu S, et al. (2018): MicroRNA132 associated multimodal neuroimaging patterns in unmedicated major depressive disorder. Brain.

85. Sui J, Adali T, Yu Q, Chen J, Calhoun VD (2012): A review of multivariate methods for multimodal fusion of brain imaging data. Journal of neuroscience methods. 204:68-81.

86. Jiang R, Calhoun VD, Cui Y, Qi S, Zhuo C, Li J, et al. (2019): Multimodal data revealed different neurobiological correlates of intelligence between males and females. Brain imaging and behavior.

87. Sui J, Qi S, van Erp TGM, Bustillo J, Jiang R, Lin D, et al. (2018): Multimodal neuromarkers in schizophrenia via cognition-guided MRI fusion. Nature communications. 9:3028.

88. Abi-Dargham A, Horga G (2016): The search for imaging biomarkers in psychiatric disorders. Nature medicine. 22:1248-1255.

89. Poldrack RA, Baker CI, Durnez J, Gorgolewski KJ, Matthews PM, Munafo MR, et al. (2017): Scanning the horizon: towards transparent and reproducible neuroimaging research. Nat Rev Neurosci. 18:115-126.

90. Poldrack RA, Gorgolewski KJ (2014): Making big data open: data sharing in neuroimaging. Nat Neurosci. 17:1510-1517.

91. Dadi K, Rahim M, Abraham A, Chyzhyk D, Milham M, Thirion B, et al. (2019): Benchmarking functional connectome-based predictive models for resting-state fMRI. Neuroimage. 192:115-134.

92. Liegeois R, Li J, Kong R, Orban C, Van De Ville D, Ge T, et al. (2019): Resting brain dynamics at different timescales capture distinct aspects of human behavior. Nature communications. 10:2317.

93. Zuo XN, Xu T, Milham MP (2019): Harnessing reliability for neuroscience research. Nat Hum Behav. 3:768-771.

94. Chu C, Ni Y, Tan G, Saunders CJ, Ashburner J (2011): Kernel regression for fMRI pattern prediction. Neuroimage. 56:662-673.

95. Li J, Kong R, Liegeois R, Orban C, Tan Y, Sun N, et al. (2019): Global signal regression strengthens association between resting-state functional connectivity and behavior. Neuroimage. 196:126-141.

96. Gao S, Greene AS, Constable RT, Scheinost D (2019): Combining multiple connectomes improves predictive modeling of phenotypic measures. Neuroimage. 201:116038. 
97. Jiang R, Zuo N, Ford JM, Qi S, Zhi D, Zhuo C, et al. (2019): Task-induced brain connectivity promotes the detection of individual differences in brain-behavior relationships. NeuroImage.116370.

98. Plis SM, Hjelm DR, Salakhutdinov R, Allen EA, Bockholt HJ, Long JD, et al. (2014): Deep learning for neuroimaging: a validation study. Front Neurosci. 8:229.

99. Yan W, Calhoun V, Song M, Cui Y, Yan H, Liu S, et al. (2019): Discriminating schizophrenia using recurrent neural network applied on time courses of multi-site FMRI data. EBioMedicine. 47:543-552.

100. Cole JH, Poudel RPK, Tsagkrasoulis D, Caan MWA, Steves C, Spector TD, et al. (2017): Predicting brain age with deep learning from raw imaging data results in a reliable and heritable biomarker. Neuroimage. 163:115-124.

101. He T, Kong R, Holmes AJ, Sabuncu MR, Eickhoff SB, Bzdok D, et al. (2018): Is deep learning better than kernel regression for functional connectivity prediction of fluid intelligence? 2018 International Workshop on Pattern Recognition in Neuroimaging (PRNI), pp 1-4.

102. Horien C, Shen X, Scheinost D, Constable RT (2019): The individual functional connectome is unique and stable over months to years. Neuroimage. 189:676-687. 
bioRxiv preprint doi: https://doi.org/10.1101/2020.02.22.961136; this version posted February 25,2020 . The copyright holder for this preprint (which was not certified by peer review) is the author/funder, who has granted bioRxiv a license to display the preprint in perpetuity. It is made available under aCC-BY-NC-ND 4.0 International license.

\section{Neuroimaging-based Individualized Prediction of Cognition and Behavior for Mental Disorders and Health: Methods and Promises}

\section{Supplementary File}

Table S1. Summary of 122 regression-based prediction studies

\begin{tabular}{|c|c|c|c|c|}
\hline Method & Behavior measure & Number of Subjects & Prediction accuracy & Reference \\
\hline \multicolumn{5}{|l|}{ fMRI } \\
\hline \multirow{25}{*}{$\begin{array}{l}\text { Simple/multiple } \\
\text { linear regression }\end{array}$} & \begin{tabular}{|l|} 
General ability \\
Flexibility \\
Memory \\
\end{tabular} & $2013 \mathrm{HC}$ & $\begin{array}{l}0.31 \\
0.06 \\
0.15\end{array}$ & (1) \\
\hline & Fluid intelligence & $\begin{array}{l}515 \mathrm{HC} \\
571 \mathrm{HC}\end{array}$ & $\begin{array}{c}0.3578 \\
0.351\end{array}$ & (2) \\
\hline & Fluid intelligence & $606 \mathrm{HC}$ & 0.22 & (3) \\
\hline & Fluid intelligence & $316 \mathrm{HC}$ & $\sim 0.20$ & (4) \\
\hline & Fluid intelligence & $126 \mathrm{HC}$ & 0.50 & $(5)$ \\
\hline & Fluid intelligence & $100 \mathrm{HC}$ & 0.72 & $(6)$ \\
\hline & Intelligence & $267 \mathrm{HC}$ & 0.61 & $(7)$ \\
\hline & $\begin{array}{l}\text { Verbal IQ/Full IQ } \\
\text { Verbal IQ/Full IQ }\end{array}$ & $226 \mathrm{HC}$ & $\begin{array}{l}0.54 / 0.26 \\
0.27 / 0.10\end{array}$ & (8) \\
\hline & General intelligence & $\begin{array}{l}\text { Training: } 844 \mathrm{HC} \\
\text { Testing: } 100 \mathrm{HC}\end{array}$ & 0.68 & (9) \\
\hline & Intelligence & $\begin{array}{l}298 \mathrm{HC} \\
591 \mathrm{HC} \\
\text { Train: } 591 \mathrm{HC} \text {, test } 298 \mathrm{HC}\end{array}$ & $\begin{array}{l}0.28 \\
0.32 \\
0.31\end{array}$ & (10) \\
\hline & $\begin{array}{l}\text { Fluid intelligence } \\
\text { General executive ability } \\
\text { Processing speed }\end{array}$ & $810 \mathrm{HC}$ & $\begin{array}{l}0.29 \\
0.41 \\
0.20\end{array}$ & (11) \\
\hline & $\begin{array}{l}\text { Sustained attention } \\
\text { Sustained attention } \\
\text { ADHD-rating scale } \\
\text { Sustained attention } \\
\text { Sustained attention }\end{array}$ & $\begin{array}{l}25 \mathrm{HC} \\
25 \mathrm{HC} \\
\text { Train } 25 \mathrm{HC} \text {, test: } 113 \text { ADHD+HC } \\
\text { Train: } 113 \text { ADHD+HC, test: } 25 \mathrm{HC} \\
\text { Train: } 113 \text { ADHD+HC, test: } 25 \mathrm{HC}\end{array}$ & $\begin{array}{l}0.49 \\
0.87 \\
0.34 \\
0.80 \\
0.49\end{array}$ & (12) \\
\hline & $\begin{array}{l}\text { Attention: } 3 \text { components } \\
\text { Attention: } 4 \text { components }\end{array}$ & $\begin{array}{l}41 \mathrm{HC} \\
44 \mathrm{HC}\end{array}$ & $\begin{array}{c}0.49 / 0.68 / 0.34 \\
0.62 / 0.63 / 0.31 / 0.35\end{array}$ & (13) \\
\hline & Sustained attention & $140 \mathrm{HC}$ & 0.402 & (14) \\
\hline & Sustained attention & $\begin{array}{l}25 \mathrm{HC} \\
41 \mathrm{HC} \\
72 \mathrm{HC}\end{array}$ & $\begin{array}{l}0.663 \\
0.31 \\
0.34\end{array}$ & $(15)$ \\
\hline & Reading recall & $\begin{array}{l}\text { Discovery: } 19 \mathrm{HC} \\
\text { Validation: } 19 \mathrm{HC}\end{array}$ & $\begin{array}{l}0.826 \\
0.592\end{array}$ & (16) \\
\hline & Inhibitory control & $82 \mathrm{HC}$ & $\begin{array}{l}0.34 \\
0.59\end{array}$ & $(17)$ \\
\hline & Inhibitory control & $34 \mathrm{HC}$ & 0.61 & $(18)$ \\
\hline & Cognitive flexibility & $\begin{array}{l}\text { Discovery: } 550 \mathrm{HC} \\
\text { Validation: } 233 \mathrm{HC}\end{array}$ & $\begin{array}{l}0.11 \\
0.23\end{array}$ & (19) \\
\hline & Creativity & $\begin{array}{l}\text { Discovery: } 163 \mathrm{HC} \\
\text { validation } 1: 39 \mathrm{HC} \\
\text { validation } 2: 54 \mathrm{HC} \\
\text { validation } 3: 405 \mathrm{HC}\end{array}$ & $\begin{array}{l}0.30 \\
0.35 \\
0.28 \\
0.13\end{array}$ & $(20)$ \\
\hline & Neuroticism/Extraversion & $114 \mathrm{HC}$ & $0.27 / 0.22$ & $(21)$ \\
\hline & $\begin{array}{l}\text { Loneliness } \\
\text { Neuroticism/Extraversion }\end{array}$ & $75 \mathrm{HC}$ & $\begin{array}{c}0.244 \\
0.45 / 0.22\end{array}$ & $(22)$ \\
\hline & Narcissism & $155 \mathrm{HC}$ & 0.247 & $(23)$ \\
\hline & $\begin{array}{l}\text { SRS-total } \\
\text { SRS-communication } \\
\text { SRS-motivation } \\
\text { SRS-mannerism } \\
\text { SRS-awareness } \\
\text { SRS-cognition } \\
\text { ADOS-total } \\
\text { ADOS-social affect } \\
\text { ADOS-generic total score } \\
\text { ADOS-severity score } \\
\text { ADHD index score } \\
\text { ADHD inattention score } \\
\text { ADHD hyperactivity score } \\
\text { ADHD inattention } \\
\text { ADHD index score }\end{array}$ & $\begin{array}{l}352 \mathrm{ASD}+\mathrm{HC} \\
352 \mathrm{ASD}+\mathrm{HC} \\
352 \mathrm{ASD}+\mathrm{HC} \\
352 \mathrm{ASD}+\mathrm{HC} \\
260 \mathrm{ASD}+\mathrm{HC} \\
260 \mathrm{ASD}+\mathrm{HC} \\
79 \mathrm{ASD} \\
79 \mathrm{ASD} \\
79 \mathrm{ASD} \\
79 \mathrm{ASD} \\
112 \mathrm{HC}+\mathrm{ADHD} \\
112 \mathrm{HC}+\mathrm{ADHD} \\
112 \mathrm{HC}+\mathrm{ADHD} \\
65 \mathrm{ADHD}+\mathrm{HC} \\
65 \mathrm{ADHD}+\mathrm{HC}\end{array}$ & $\begin{array}{l}0.32 \\
0.30 \\
0.23 \\
0.37 \\
0.27 \\
0.27 \\
0.43 \\
0.53 \\
0.40 \\
0.60 \\
0.39 \\
0.40 \\
0.30 \\
0.31 \\
0.32\end{array}$ & (24) \\
\hline & ADAS-Cog & $19 \mathrm{HC}+29 \mathrm{MCI}+11 \mathrm{AD}$ & 0.49 & $(25)$ \\
\hline
\end{tabular}


bioRxiv preprint doi: https://doi.org/10.1101/2020.02.22.961136; this version posted February $25,2020$. The copyright holder for this preprint (which was not certified by peer review) is the author/funder, who has granted bioRxiv a license to display the preprint in perpetuity. It is made available under aCC-BY-NC-ND 4.0 International license.

\begin{tabular}{|c|c|c|c|c|}
\hline & ADOS & $58 \mathrm{ASD}$ & 0.44 & $(26)$ \\
\hline & MMSE & $133 \mathrm{AD}+198 \mathrm{HC}$ & 0.79 & $(27)$ \\
\hline \multirow{11}{*}{ LASSO } & & Discovery: $360 \mathrm{HC}$ & 0.51 & \\
\hline & & Discovery: $174 \mathrm{HC}$ & 0.72 & \\
\hline & & Discovery: $186 \mathrm{HC}$ & 0.46 & \\
\hline & Intelligence & Validation 1: $125 \mathrm{HC}$ & 0.29 & $(28)$ \\
\hline & & Validation 1: $75 \mathrm{HC}$ & 0.253 & \\
\hline & & validation 2: $42 \mathrm{HC}+\mathrm{SZ}+\mathrm{BP}$ & 0.40 & \\
\hline & & validation 2: $78 \mathrm{HC}+\mathrm{SZ}+\mathrm{BP}$ & 0.23 & \\
\hline & Fluid intelligence & $830 \mathrm{HC}$ & 0.24 & $(29)$ \\
\hline & Musical features: 5 domains & $15 \mathrm{HC}$ & $0.49 / 0.32 / 0.31 / 0.46 / 0.38$ & $(30)$ \\
\hline & $\begin{array}{l}\text { UPDRS-III medication-on } \\
\text { UPDRS-III medication-off }\end{array}$ & 62 Parkinson's disease & $\begin{array}{l}0.65 \\
0.54\end{array}$ & (31) \\
\hline & $\begin{array}{l}\text { Temperament traits: } 4 \text { domains } \\
\text { Neuroticism/Extraversion }\end{array}$ & $\begin{array}{l}\text { Discovery: } 360 \mathrm{HC} \\
\text { Validation: } 155 \mathrm{HC}\end{array}$ & $\begin{array}{c}0.61 / 0.57 / 0.61 / 0.50 \\
0.31 / 0.22\end{array}$ & $(32)$ \\
\hline \multirow{9}{*}{ Ridge regression } & Fluid intelligence & $\begin{array}{l}515 \mathrm{HC} \\
571 \mathrm{HC} \\
\text { Train:515, test } 571 \\
\text { Train } 571 \text {, test } 515\end{array}$ & $\begin{array}{l}0.436 \\
0.356 \\
\sim 0.28 \\
\sim 0.28\end{array}$ & (33) \\
\hline & $\begin{array}{l}\text { ORRT } \\
\text { Impulsivity } \\
\text { Fluid intelligence } \\
\text { PVT }\end{array}$ & $577 \mathrm{HC}$ & $\begin{array}{c}0.2918 \\
0.2398 \\
0.21 \\
0.21\end{array}$ & (34) \\
\hline & Morality bias & $25 \mathrm{HC}$ & 0.84 & $(35)$ \\
\hline & Decision making & $18 \mathrm{HC}$ & 0.56 & $(36)$ \\
\hline & SRS & $27 \mathrm{ASD}$ & 0.38 & $(37)$ \\
\hline & Mental rotation & $862 \mathrm{HC}$ & 0.20 & \\
\hline & Vocabulary & $862 \mathrm{HC}$ & 0.22 & (38) \\
\hline & ORRT & $953 \mathrm{HC}$ & 0.40 & ) \\
\hline & PVT & $953 \mathrm{HC}$ & 0.42 & \\
\hline \multirow{4}{*}{ Elastic net } & General intelligence & $884 \mathrm{HC}$ & 0.457 & $(39)$ \\
\hline & $\begin{array}{l}\text { Working memory } \\
\text { Story comprehension } \\
\text { ORRT } \\
\text { PVT } \\
\text { Cognitive flexibility }\end{array}$ & $419 \mathrm{HC}$ & $\begin{array}{l}0.30 \\
0.30 \\
0.38 \\
0.40 \\
0.29\end{array}$ & $(40)$ \\
\hline & $\begin{array}{l}\text { Fluid intelligence } \\
\text { Openness } \\
\text { Superordinate Personality factor }\end{array}$ & $884 \mathrm{HC}$ & $\begin{array}{c}0.26 \\
0.24 \\
0.272\end{array}$ & (41) \\
\hline & $\begin{array}{l}\text { Grip strength } \\
\text { ORRT } \\
\text { PVT } \\
\text { Spatial orientation } \\
\text { Grip strength }\end{array}$ & $\begin{array}{l}794 \mathrm{HC} \\
794 \mathrm{HC} \\
794 \mathrm{HC} \\
794 \mathrm{HC} \\
160 \mathrm{HC}\end{array}$ & 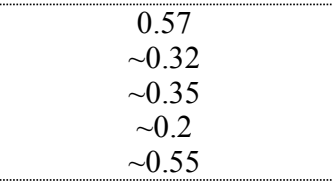 & $(42)$ \\
\hline \multirow{6}{*}{ RVR } & Unified PD Rating Scale-III & $84 \mathrm{PD}$ & 0.35 & $(43)$ \\
\hline & Aphasia quotient score & $\begin{array}{l}77 \text { low-grade gliomas } \\
49 \text { high-grade gliomas }\end{array}$ & $\begin{array}{l}0.299 \\
0.521\end{array}$ & (44) \\
\hline & $\begin{array}{l}\text { Visuospatial divergent thinking } \\
\text { Visuospatial divergent thinking } \\
\text { Verbal divergent thinking } \\
\text { Verbal divergent thinking }\end{array}$ & $\begin{array}{l}242 \mathrm{HC} \\
260 \mathrm{HC} \\
242 \mathrm{HC} \\
260 \mathrm{HC}\end{array}$ & $\begin{array}{l}0.21 \\
0.20 \\
0.29 \\
0.19\end{array}$ & $(45)$ \\
\hline & $\begin{array}{l}\text { Trust } \\
\text { Horizontal collectivism }\end{array}$ & $83 \mathrm{HC}$ & $\begin{array}{l}0.27 \\
0.31\end{array}$ & (46) \\
\hline & Deception & $47 \mathrm{HC}$ & 0.48 & $(47)$ \\
\hline & Openness/Extraversion/Neuroticism & $\begin{array}{l}310 \mathrm{HC} \\
151 \mathrm{HC}\end{array}$ & $\begin{array}{l}0.17 / 0.29 / 0.20 \\
0.29 / 0.23 / 0.42\end{array}$ & $(48)$ \\
\hline \multirow{10}{*}{ SVR } & Distractibility & $32 \mathrm{HC}$ & 0.48 & $(49)$ \\
\hline & Multitasking ability & $106 \mathrm{HC}$ & 0.40 & $(50)$ \\
\hline & $\begin{array}{l}\text { Interoception intensity } \\
\text { Anxiety feeling }\end{array}$ & $122 \mathrm{HC}$ & $\begin{array}{l}0.2576 \\
0.2471\end{array}$ & $(51)$ \\
\hline & Self-Rating Anxiety/Depression Scale & $\begin{array}{l}44 \mathrm{HC}: \text { time } 1 \\
44 \mathrm{HC}: \text { time } 2\end{array}$ & $\begin{array}{l}0.748 / 0.757 \\
0.727 / 0.751\end{array}$ & $(52)$ \\
\hline & HDRS & 24 Depression $+29 \mathrm{HC}$ & 0.91 & $(53)$ \\
\hline & Fluid intelligence & $677 \mathrm{HC}$ & 0.347 & $(54)$ \\
\hline & $\begin{array}{l}\text { Fluid intelligence } \\
\text { Cognitive flexibility } \\
\text { Inhibition }\end{array}$ & $105 \mathrm{HC}$ & $\begin{array}{l}0.418 \\
0.490 \\
0.307\end{array}$ & $(55)$ \\
\hline & $\begin{array}{l}\text { Fluid intelligence } \\
\text { ORRT } \\
\text { Grip strength } \\
\text { Anger-aggression }\end{array}$ & $472 \mathrm{HC}$ & $\begin{array}{l}0.431 \\
0.425 \\
0.512 \\
0.258\end{array}$ & $(56)$ \\
\hline & $\begin{array}{l}\text { PANSS positive/negative } \\
\text { PANSS positive /YMRS }\end{array}$ & $76 \mathrm{SZ}$ & $\begin{array}{l}0.50 / 0.35 \\
0.35 / 0.51\end{array}$ & $(57)$ \\
\hline & YBOCS (obsessive compulsive scale) & $41 \mathrm{OCD}$ & 0.528 & $(58)$ \\
\hline
\end{tabular}


bioRxiv preprint doi: https://doi.org/10.1101/2020.02.22.961136; this version posted February $25,2020$. The copyright holder for this preprint (which was not certified by peer review) is the author/funder, who has granted bioRxiv a license to display the preprint in perpetuity. It is made available under aCC-BY-NC-ND 4.0 International license.

\begin{tabular}{|c|c|c|c|c|}
\hline & $\begin{array}{l}\text { YBOCS change } \\
\text { DOCS (OCD severity): } 2 \text { dimensions } \\
\text { DOCS change }\end{array}$ & & $\begin{array}{c}0.374 \\
0.333 / 0.337 \\
0.359\end{array}$ & \\
\hline \multirow[t]{2}{*}{ PLSR } & Sustained attention & $\begin{array}{l}\text { Discovery: } 25 \mathrm{HC} \\
\text { Validation } 1: 86 \mathrm{HC} \\
\text { Validation } 2: 41 \mathrm{HC} \\
\text { Validation } 3: 113 \mathrm{ADHD}+\mathrm{HC}\end{array}$ & $\begin{array}{l}0.908 \\
0.576 \\
0.631 \\
0.413\end{array}$ & $(59)$ \\
\hline & $\begin{array}{l}\text { BDI-II } \\
\text { SHAPS } \\
\text { PANSS }\end{array}$ & $58 \mathrm{MDD}+65 \mathrm{HC}$ & $\begin{array}{c}0.5416 \\
0.591 \\
0.563\end{array}$ & $(60)$ \\
\hline PLSR & Long-term memory & $55 \mathrm{MCI}$ & 0.641 & $(61)$ \\
\hline \multirow[b]{2}{*}{ GSR } & Inhibition control & $36 \mathrm{HC}$ & 0.49 & $(62)$ \\
\hline & $\begin{array}{l}\text { State anxiety scores } \\
\text { Mood and Anxiety Symptom } \\
\text { HDRS for Anxiety }\end{array}$ & 82 distressed adults, $72 \mathrm{HC}$ & $\begin{array}{l}0.28 \\
0.28 \\
0.24\end{array}$ & $(63)$ \\
\hline Deep learning & $\begin{array}{l}\text { Working memory } \\
\text { Relational performance } \\
\text { Language performance } \\
\text { Social performance }\end{array}$ & $\begin{array}{l}473 \mathrm{HC} \\
457 \mathrm{HC} \\
471 \mathrm{HC} \\
473 \mathrm{HC}\end{array}$ & $\begin{array}{c}0.536 \\
0.357 \\
0.375 \\
0.28\end{array}$ & $(64)$ \\
\hline \multirow[b]{2}{*}{$\begin{array}{l}\text { Sparse linear } \\
\text { regression }\end{array}$} & Working memory & $17 \mathrm{HC}$ & 0.8567 & $(65)$ \\
\hline & Working memory & $\begin{array}{l}\text { Train: } 17 \mathrm{HC} \text {, test: } 474 \mathrm{HC} \\
\text { Train: } 17 \mathrm{HC} \text {, test: } 58 \mathrm{SZ}\end{array}$ & $\begin{array}{l}0.110 \\
0.248\end{array}$ & $(66)$ \\
\hline \multirow[b]{2}{*}{$\begin{array}{l}\text { Multiple Kernel } \\
\text { Learning }\end{array}$} & Negative affect personality & $34 \mathrm{HC} \quad-\quad-\quad-\quad$ & 0.52 & $(67)$ \\
\hline & Energy-Manic Symptom Severity & $\begin{array}{l}56 \text { distressed adults } \\
36 \text { distressed adults }\end{array}$ & $\begin{array}{l}0.42 \\
0.33\end{array}$ & $(68)$ \\
\hline \multicolumn{5}{|l|}{ SMRI } \\
\hline \multirow{3}{*}{$\begin{array}{l}\text { Simple/multiple } \\
\text { linear regression }\end{array}$} & Inhibition & $42 \mathrm{HC}$ & $\sim 0.6$ & $(69)$ \\
\hline & Anxiety score & $76 \mathrm{HC}$ & 0.40 & $(70)$ \\
\hline & Inhibitory control & $\begin{array}{l}\text { Discovery: } 214 \mathrm{HC} \\
\text { Validation: } 117 \mathrm{HC}\end{array}$ & $\begin{array}{c}0.3237 \\
0.46\end{array}$ & $(71)$ \\
\hline \multirow{6}{*}{ SVR } & OCD Symptom severity: 2 tests & 37 OCD & $0.49 / 0.44$ & $(72)$ \\
\hline & ADOS & $82 \mathrm{ASD}$ & 0.362 & $(73)$ \\
\hline & IQ & $164 \mathrm{HC}$ & 0.718 & $(74)$ \\
\hline & Learning success & $34 \mathrm{HC}$ & 0.74 & $(75)$ \\
\hline & Resilience & 41 Ultra-high Risk subjects & 0.42 & $(76)$ \\
\hline & 3 reading components & $253 \mathrm{HC}$ & $0.26 / 0.23 / 0.24$ & $(77)$ \\
\hline \multirow[t]{6}{*}{ RVR } & $\begin{array}{l}\text { MMSE } \\
\text { DRS } \\
\text { AVLT } \\
\text { MMSE } \\
\text { DRS } \\
\text { MMSE } \\
\text { ADAS } \\
\text { MMSE } \\
\text { ADAS } \\
\text { MMSE } \\
\text { MMSE } \\
\text { ADAS } \\
\text { AVLT }\end{array}$ & $\begin{array}{l}73 \mathrm{AD}+91 \mathrm{HC} \\
73 \mathrm{AD}+91 \mathrm{HC} \\
73 \mathrm{AD}+91 \mathrm{HC} \\
73 \mathrm{AD} \\
73 \mathrm{AD} \\
113 \mathrm{AD}+351 \mathrm{MCI}+122 \mathrm{HC} \\
113 \mathrm{AD}+351 \mathrm{MCI}+122 \mathrm{HC} \\
39 \mathrm{AD}+92 \mathrm{MCI}+32 \mathrm{HC} \\
39 \mathrm{AD}, 92 \mathrm{MCI}+32 \mathrm{HC} \\
\text { Train: } 164 \text {, test: } 234 \\
\text { Train: } 234 \text {, test: } 164 \\
\text { Train: } 586 \text {, test: } 164 \\
\text { Train: } 164 \text {, test: } 586\end{array}$ & $\begin{array}{l}0.7 \\
0.73 \\
0.60 \\
0.44 \\
0.54 \\
0.48 \\
0.57 \\
0.47 \\
0.49 \\
0.56 \\
0.60 \\
0.62 \\
0.40\end{array}$ & $(78)$ \\
\hline & $\begin{array}{l}\text { HDRS } \\
\text { MADRS }\end{array}$ & 20 Depression & $\begin{array}{l}0.5071 \\
0.5441\end{array}$ & $(79)$ \\
\hline & $\begin{array}{l}\text { MMSE } \\
\text { Boston Naming Testing }\end{array}$ & $\begin{array}{l}23 \mathrm{AD}+74 \mathrm{MCI}+22 \mathrm{HC} \\
22 \mathrm{AD}+31 \mathrm{MCI}+16 \mathrm{HC}\end{array}$ & $\begin{array}{l}0.7386 \\
0.5891\end{array}$ & $(80)$ \\
\hline & PANSS total score & 50 ultra-high risk subjects & 0.34 & $(81)$ \\
\hline & BDI & $30 \mathrm{MDD}$ & 0.694 & $(82)$ \\
\hline & Cognitive flexibility & $100 \mathrm{HC}$ & 0.41 & $(83)$ \\
\hline LASSO & Learning biases & $41 \mathrm{HC}$ & 0.58 & $(84)$ \\
\hline \multirow{4}{*}{ Ridge regression } & $\begin{array}{l}\text { Motor: } 2 \text { domains } \\
\text { Language } \\
\text { visuospatial memory } \\
\text { verbal memory } \\
\text { Attention }\end{array}$ & $\begin{array}{l}117 \text { Stroke } \\
124 \text { Stroke } \\
98 \text { Stroke } \\
98 \text { Stroke } \\
101 \text { Stroke }\end{array}$ & $\begin{array}{l}0.73 / 0.51 \\
0.66 \\
0.41 \\
0.2 \\
0.58\end{array}$ & $(85)$ \\
\hline & Effortful control & $246 \mathrm{HC}$ & 0.24 & $(86)$ \\
\hline & Fear of pain & $99 \mathrm{HC}$ & 0.41 & $(87)$ \\
\hline & $\begin{array}{l}\text { Attention } \\
\text { Visual memory } \\
\text { Verbal memory } \\
\text { Language } \\
\text { Motor }\end{array}$ & $\begin{array}{l}80 \text { Stroke } \\
79 \text { Stroke } \\
79 \text { Stroke } \\
98 \text { Stroke } \\
91 \text { Stroke }\end{array}$ & $\begin{array}{l}0.6708 \\
0.6033 \\
0.6450 \\
0.7148 \\
0.4837\end{array}$ & $(88)$ \\
\hline \multirow[b]{2}{*}{ Elastic net } & $\begin{array}{l}\text { RAVLT Immediate } \\
\text { RAVLT-Percent Forgetting }\end{array}$ & $\begin{array}{l}186 \mathrm{AD}+394 \mathrm{MCI}+226 \mathrm{HC} \\
180 \mathrm{AD}+393 \mathrm{MC}+226 \mathrm{HC}\end{array}$ & $\begin{array}{l}0.50 \\
0.43\end{array}$ & $(89)$ \\
\hline & $\begin{array}{l}\text { ORRT } \\
\text { PVT } \\
\text { ORRT }\end{array}$ & $\begin{array}{l}\text { Discovery: } 507 \mathrm{HC} \\
\text { Discovery: } 507 \mathrm{HC} \\
\text { Validation } 1: 372 \mathrm{HC}\end{array}$ & $\begin{array}{l}0.40 \\
0.43 \\
0.28\end{array}$ & $(90)$ \\
\hline
\end{tabular}


bioRxiv preprint doi: https://doi.org/10.1101/2020.02.22.961136; this version posted February $25,2020$. The copyright holder for this preprint (which was not certified by peer review) is the author/funder, who has granted bioRxiv a license to display the preprint in perpetuity. It is made available under aCC-BY-NC-ND 4.0 International license.

\begin{tabular}{|c|c|c|c|c|}
\hline & $\begin{array}{l}\text { PVT } \\
\text { Reading decoding } \\
\text { Vocabulary }\end{array}$ & $\begin{array}{l}\text { Validation: } 1: 372 \mathrm{HC} \\
\text { Validation 2: } 41 \mathrm{HC}+25 \text { Dyslexia } \\
\text { Validation 2: } 41 \mathrm{HC}+25 \text { Dyslexia }\end{array}$ & $\begin{array}{l}0.34 \\
0.24 \\
0.20\end{array}$ & \\
\hline & ADOS symptom & $156 \mathrm{ASD}$ & 0.51 & $(91)$ \\
\hline PLSR & IQ & $78 \mathrm{HC}$ & 0.55 & $(92)$ \\
\hline Deep learning & $\begin{array}{l}\text { ADAS } \\
\text { MMSE } \\
\text { ADAS } \\
\text { MMSE }\end{array}$ & $\begin{array}{l}198 \mathrm{HC}+326 \mathrm{MCI}+145 \mathrm{AD} \\
198 \mathrm{HC}+326 \mathrm{MCI}+145 \mathrm{AD} \\
256 \mathrm{HC}+311 \mathrm{MCI}+23 \mathrm{AD} \\
256 \mathrm{HC}+311 \mathrm{MCI}+23 \mathrm{AD}\end{array}$ & $\begin{array}{l}0.60 \\
0.52 \\
0.68 \\
0.55\end{array}$ & (93) \\
\hline NG-L21 & $\begin{array}{l}\text { MMSE; } \\
\text { RAVLT: } 5 \text { domains } \\
\text { logical memory }\end{array}$ & $179 \mathrm{AD}+205 \mathrm{HC}$ & $\begin{array}{c}0.7574 \\
0.65 / 0.59 / 0.56 / 0.61 / 0.46 \\
0.707\end{array}$ & (94) \\
\hline G-SMuRFS & $\begin{array}{l}\text { ADAS total scores } \\
\text { MMSE } \\
\text { RAVLT: } 3 \text { domains }\end{array}$ & $197 \mathrm{HC}+349 \mathrm{MCI}+172 \mathrm{AD}$ & $\begin{array}{c}0.644 \\
0.554 \\
0.526 / 0.474 / 0.395\end{array}$ & $(95)$ \\
\hline CORNLIN & $\begin{array}{l}\text { ADAS } \\
\text { MMSE, } \\
\text { RAVLT: } 3 \text { domains } \\
\text { TRAILS: } 3 \text { domains } \\
\end{array}$ & $171 \mathrm{AD}+222 \mathrm{HC}$ & $\begin{array}{c}0.767 \\
0.758 \\
0.633 / 0.608 / 0.598 \\
0.562 / 0.607 / 0.525\end{array}$ & $(96)$ \\
\hline MMR & $\begin{array}{l}\text { Fluency } \\
\text { RAVLT } \\
\text { TRAILS }\end{array}$ & $225 \mathrm{HC}+393 \mathrm{MCI}+186 \mathrm{AD}$ & $\begin{array}{l}0.5427 \\
0.8865 \\
0.5796\end{array}$ & $(97)$ \\
\hline FGL-MTFL & $\begin{array}{l}\text { ADAS } \\
\text { MMSE } \\
\text { TOTAL } \\
\text { ANIM }\end{array}$ & $173 \mathrm{AD}+225 \mathrm{HC}+390 \mathrm{MCI}$ & $\begin{array}{l}0.667 \\
0.548 \\
0.522 \\
0.399\end{array}$ & $(98)$ \\
\hline \multicolumn{5}{|l|}{ dMRI } \\
\hline Linear regression & $\begin{array}{l}\text { ORRT } \\
\text { PVT } \\
\text { Line orientation }\end{array}$ & $1065 \mathrm{HC}$ & $\begin{array}{l}0.3020 \\
0.2622 \\
0.2536\end{array}$ & (99) \\
\hline Ridge regression & Trait anxiety & $72 \mathrm{HC}$ & 0.25 & $(100)$ \\
\hline LASSO & $\begin{array}{l}\text { Episodic memory } \\
\text { Spatial orientation }\end{array}$ & $840 \mathrm{HC}$ & $\begin{array}{l}0.0977 \\
0.0951\end{array}$ & $(101)$ \\
\hline SVR & $\begin{array}{l}\text { YTO-L } \\
\text { YTO-A }\end{array}$ & $39 \mathrm{HD}$ & $\begin{array}{c}0.6613 \\
0.622\end{array}$ & $(102)$ \\
\hline RVR & Dispositional worry & $59 \mathrm{HC}$ & 0.41 & $(103)$ \\
\hline Deep learning & $\begin{array}{l}\text { Bayley-III motor } \\
\text { Bayley-III cognition }\end{array}$ & $168 \mathrm{HC}$ & $\begin{array}{c}0.31 \\
0.188 \\
\end{array}$ & $(104)$ \\
\hline \multicolumn{5}{|l|}{ Multimodal } \\
\hline \multirow{4}{*}{$\begin{array}{l}\text { Simple/multiple } \\
\text { linear regression }\end{array}$} & IQ & $\begin{array}{l}160 \mathrm{HC} \\
166 \mathrm{HC}\end{array}$ & $\begin{array}{l}0.45 \\
0.45 \\
\end{array}$ & $(105)$ \\
\hline & $\begin{array}{l}\text { MCCB composite } \\
\text { MCCB social cognition } \\
\text { PANSS positive } \\
\text { PANSS negative }\end{array}$ & $\begin{array}{l}47 \mathrm{SZ}+50 \mathrm{HC} \\
47 \mathrm{SZ}+50 \mathrm{HC} \\
47 \mathrm{SZ} \\
47 \mathrm{SZ}\end{array}$ & $\begin{array}{l}0.70 \\
0.7084 \\
0.7785 \\
0.7804\end{array}$ & $(106)$ \\
\hline & $\begin{array}{l}\text { Cognitive composite } \\
\text { Speed of processing } \\
\text { Cognitive composite } \\
\text { Speed of processing }\end{array}$ & $\begin{array}{l}\text { Discovery: } 147 \mathrm{SZ}+147 \mathrm{HC} \\
\text { Discovery: } 147 \mathrm{SZ}+147 \mathrm{HC} \\
\text { Validation: } 46 \mathrm{SZ}+42 \mathrm{HC} \\
\text { Validation: } 46 \mathrm{SZ}+42 \mathrm{HC}\end{array}$ & $\begin{array}{l}0.463 \\
0.470 \\
0.406 \\
0.351\end{array}$ & $(107)$ \\
\hline & $\begin{array}{l}\text { Working memory } \\
\text { Verbal learning } \\
\text { Composite cognition }\end{array}$ & $94 \mathrm{SZ}+83 \mathrm{HC}$ & $\begin{array}{l}0.235 \\
0.25 \\
0.256\end{array}$ & $(108)$ \\
\hline Ridge regression & Trait anxiety & $531 \mathrm{HC}$ & 0.26 & $(109)$ \\
\hline Elastic net & Creativity & $\begin{array}{l}\text { Discovery: } 138 \mathrm{HC} \\
\text { Validation: } 98 \mathrm{HC}\end{array}$ & $\begin{array}{c}0.5238 \\
0.267\end{array}$ & (110) \\
\hline \multirow[t]{3}{*}{ SVR } & $\begin{array}{l}\text { Working memory } \\
\text { MMSE } \\
\text { ADAS-Cog } \\
\text { MMSE } \\
\text { ADAS-Cog } \\
\text { MMSE } \\
\text { ADAS }\end{array}$ & $\begin{array}{l}46 \mathrm{HC} \\
51 \mathrm{AD}+52 \mathrm{HC} \\
51 \mathrm{AD}+52 \mathrm{HC} \\
99 \mathrm{MCI}+52 \mathrm{HC} \\
99 \mathrm{MCI}+52 \mathrm{HC} \\
99 \mathrm{MCI} \\
99 \mathrm{MCI}\end{array}$ & $\begin{array}{l}0.64 \\
0.685 \\
0.668 \\
0.456 \\
0.470 \\
0.584 \\
0.556 \\
\end{array}$ & $(112)$ \\
\hline & $\begin{array}{l}\text { MMSE } \\
\text { ADAS-Cog }\end{array}$ & $88 \mathrm{MCI}$ & $\begin{array}{l}0.786 \\
0.777 \\
\end{array}$ & $(113)$ \\
\hline & $\begin{array}{l}\text { Western Aphasia Battery: } 4 \text { domains } \\
\text { Aphasia quotient }\end{array}$ & 90 Aphasia result from Stroke & $\begin{array}{c}0.746 / 0.483 / 0.619 / 0.584 \\
0.694\end{array}$ & $(114)$ \\
\hline \multirow[b]{2}{*}{ RVR } & $\begin{array}{l}\text { MMSE } \\
\text { ADAS-Cog }\end{array}$ & $51 \mathrm{AD}+99 \mathrm{MCI}+52 \mathrm{HC}$ & $\begin{array}{l}0.80 \\
0.78\end{array}$ & $(115)$ \\
\hline & $\begin{array}{l}\text { Long-term memory } \\
\text { Short-term memory } \\
\text { Semantic retrieval } \\
\text { Manipulation }\end{array}$ & $\begin{array}{l}80 \mathrm{HC} \\
85 \mathrm{HC} \\
75 \mathrm{HC} \\
80 \mathrm{HC}\end{array}$ & $\begin{array}{l}0.41 \\
0.45 \\
0.46 \\
0.35\end{array}$ & $(116)$ \\
\hline PLSR & Sustained attention & $\begin{array}{l}\text { Discovery: } 25 \mathrm{HC} \\
\text { Validation } 1: 44 \mathrm{HC}\end{array}$ & $\begin{array}{l}0.86 \\
0.66\end{array}$ & $(117)$ \\
\hline
\end{tabular}


bioRxiv preprint doi: https://doi.org/10.1101/2020.02.22.961136; this version posted February 25, 2020. The copyright holder for this preprint (which was not certified by peer review) is the author/funder, who has granted bioRxiv a license to display the preprint in perpetuity. It is made available under aCC-BY-NC-ND 4.0 International license.

\begin{tabular}{|c|c|c|c|c|}
\hline & & Validation 2: $24 \mathrm{HC}$ & 0.41 & \\
\hline & Processing speed & 60 multiple sclerosis & 0.88 & (118) \\
\hline Random forest & Picture naming & 53 Stroke & 0.66 & (119) \\
\hline GGML & $\begin{array}{l}\text { MMSE } \\
\text { ADAS-Cog } \\
\text { MMSE } \\
\text { ADAS-Cog }\end{array}$ & $\begin{array}{l}50 \mathrm{AD}+52 \mathrm{HC} \\
50 \mathrm{AD}+52 \mathrm{HC} \\
97 \mathrm{MCI}+52 \mathrm{HC} \\
97 \mathrm{MCI}+52 \mathrm{HC}\end{array}$ & $\begin{array}{l}0.745 \\
0.740 \\
0.392 \\
0.472 \\
\end{array}$ & (120) \\
\hline M3T & $\begin{array}{l}\text { MMSE } \\
\text { ADAS-Cog }\end{array}$ & $45 \mathrm{AD}+91 \mathrm{MCI}+50 \mathrm{HC}$ & $\begin{array}{l}0.697 \\
0.739 \\
\end{array}$ & $(121)$ \\
\hline MKMTL & $\begin{array}{l}\text { ADAS } \\
\text { MMSE } \\
\text { FLUANIM } \\
\text { TRAILS: } 2 \text { domains } \\
\text { RAVLT Total } \\
\text { RAVLT: } 3 \text { domains }\end{array}$ & $756 \mathrm{AD}$ & $\begin{array}{c}0.721 \\
0.574 \\
0.512 \\
0.445 / 0.589 \\
0.637 \\
0.593 / 0.575 / 0.479\end{array}$ & (122) \\
\hline
\end{tabular}

\section{References}

1. Sripada C, Rutherford S, Angstadt M, Thompson WK, Luciana M, Weigard A, et al. (2019): Prediction of neurocognition in youth from resting state fMRI. Molecular psychiatry.

2. Greene AS, Gao S, Scheinost D, Constable RT (2018): Task-induced brain state manipulation improves prediction of individual traits. Nature communications. 9:2807.

3. Noble S, Spann MN, Tokoglu F, Shen X, Constable RT, Scheinost D (2017): Influences on the Test-Retest Reliability of Functional Connectivity MRI and its Relationship with Behavioral Utility. Cereb Cortex. 27:5415-5429.

4. Yoo K, Rosenberg MD, Noble S, Scheinost D, Constable RT, Chun MM (2019): Multivariate approaches improve the reliability and validity of functional connectivity and prediction of individual behaviors. Neuroimage. 197:212-223.

5. Finn ES, Shen X, Scheinost D, Rosenberg MD, Huang J, Chun MM, et al. (2015): Functional connectome fingerprinting: identifying individuals using patterns of brain connectivity. Nat Neurosci. 18:1664-1671.

6. Amico E, Goni J (2018): The quest for identifiability in human functional connectomes. Scientific reports. $8: 8254$.

7. Cai B, Zhang G, Hu W, Zhang A, Zille P, Zhang Y, et al. (2019): Refined measure of functional connectomes for improved identifiability and prediction. Hum Brain Mapp. 40:4843-4858.

8. Dryburgh E, McKenna S, Rekik I (2019): Predicting full-scale and verbal intelligence scores from functional Connectomic data in individuals with autism Spectrum disorder. Brain imaging and behavior.

9. Sripada C, Angstadt M, Rutherford SJB (2018): Towards a" Treadmill Test" for Cognition: Reliable Prediction of Intelligence From Whole-Brain Task Activation Patterns.412056.

10. Elliott ML, Knodt AR, Cooke M, Kim MJ, Melzer TR, Keenan R, et al. (2019): General functional connectivity: Shared features of resting-state and task fMRI drive reliable and heritable individual differences in functional brain networks. Neuroimage. 189:516-532.

11. Sripada C, Angstadt M, Rutherford S, Kessler D, Kim Y, Yee M, et al. (2019): Basic Units of InterIndividual Variation in Resting State Connectomes. Scientific reports. 9:1900.

12. Rosenberg MD, Finn ES, Scheinost D, Papademetris X, Shen X, Constable RT, et al. (2016): A neuromarker of sustained attention from whole-brain functional connectivity. Nat Neurosci. 19:165-171.

13. Rosenberg MD, Hsu WT, Scheinost D, Todd Constable R, Chun MM (2018): Connectome-based Models Predict Separable Components of Attention in Novel Individuals. J Cogn Neurosci. 30:160-173.

14. Fortenbaugh FC, Rothlein D, McGlinchey R, DeGutis J, Esterman M (2018): Tracking behavioral and neural fluctuations during sustained attention: A robust replication and extension. Neuroimage. 171:148-164.

15. Kumar S, Yoo K, Rosenberg MD, Scheinost D, Constable RT, Zhang S, et al. (2019): An information network flow approach for measuring functional connectivity and predicting behavior. Brain and behavior. 9:e01346. 
16. Jangraw DC, Gonzalez-Castillo J, Handwerker DA, Ghane M, Rosenberg MD, Panwar P, et al. (2018): A functional connectivity-based neuromarker of sustained attention generalizes to predict recall in a reading task. Neuroimage. 166:99-109.

17. Rosenberg MD, Zhang S, Hsu WT, Scheinost D, Finn ES, Shen X, et al. (2016): Methylphenidate Modulates Functional Network Connectivity to Enhance Attention. J Neurosci. 36:9547-9557.

18. Fountain-Zaragoza S, Samimy S, Rosenberg MD, Prakash RS (2019): Connectome-based models predict attentional control in aging adults. Neuroimage. 186:1-13.

19. Chen OY, Cao H, Reinen JM, Qian T, Gou J, Phan H, et al. (2019): Resting-state brain information flow predicts cognitive flexibility in humans. Scientific reports. 9:3879.

20. Beaty RE, Kenett YN, Christensen AP, Rosenberg MD, Benedek M, Chen Q, et al. (2018): Robust prediction of individual creative ability from brain functional connectivity. Proc Natl Acad Sci US A.

21. Hsu WT, Rosenberg MD, Scheinost D, Constable RT, Chun MM (2018): Resting-state functional connectivity predicts neuroticism and extraversion in novel individuals. Social cognitive and affective neuroscience. 13:224-232.

22. Feng C, Wang L, Li T, Xu P (2019): Connectome-based individualized prediction of loneliness. Social cognitive and affective neuroscience. 14:353-365.

23. Feng C, Yuan J, Geng H, Gu R, Zhou H, Wu X, et al. (2018): Individualized prediction of trait narcissism from whole-brain resting-state functional connectivity. Hum Brain Mapp.

24. Lake EMR, Finn ES, Noble SM, Vanderwal T, Shen X, Rosenberg MD, et al. (2019): The Functional Brain Organization of an Individual Allows Prediction of Measures of Social Abilities Transdiagnostically in Autism and Attention-Deficit/Hyperactivity Disorder. Biological psychiatry. 86:315-326.

25. Lin Q, Rosenberg MD, Yoo K, Hsu TW, O'Connell TP, Chun MM (2018): Resting-State Functional Connectivity Predicts Cognitive Impairment Related to Alzheimer's Disease. Frontiers in aging neuroscience. 10:94.

26. Yahata N, Morimoto J, Hashimoto R, Lisi G, Shibata K, Kawakubo Y, et al. (2016): A small number of abnormal brain connections predicts adult autism spectrum disorder. Nature communications. 7:11254.

27. Duc NT, Ryu S, Qureshi MNI, Choi M, Lee KH, Lee B (2019): 3D-Deep Learning Based Automatic Diagnosis of Alzheimer's Disease with Joint MMSE Prediction Using Resting-State fMRI. Neuroinformatics. 28. Jiang R, Calhoun VD, Fan L, Zuo N, Jung R, Qi S, et al. (2019): Gender Differences in Connectomebased Predictions of Individualized Intelligence Quotient and Sub-domain Scores. Cerebral Cortex.

29. Ferguson MA, Anderson JS, Spreng RN (2017): Fluid and flexible minds: Intelligence reflects synchrony in the brain's intrinsic network architecture. Netw Neurosci. 1:192-207.

30. Toiviainen P, Alluri V, Brattico E, Wallentin M, Vuust P (2014): Capturing the musical brain with Lasso: Dynamic decoding of musical features from fMRI data. Neuroimage. 88:170-180.

31. Li X, Xiong Y, Liu S, Zhou R, Hu Z, Tong Y, et al. (2019): Predicting the Post-therapy Severity Level (UPDRS-III) of Patients With Parkinson's Disease After Drug Therapy by Using the Dynamic Connectivity Efficiency of fMRI. Frontiers in Neurology. 10.

32. Jiang R, Calhoun VD, Zuo N, Lin D, Li J, Fan L, et al. (2018): Connectome-based individualized prediction of temperament trait scores. Neuroimage. 183:366-374.

33. Gao S, Greene AS, Constable RT, Scheinost D (2019): Combining multiple connectomes improves predictive modeling of phenotypic measures. Neuroimage. 201:116038.

34. Kong R, Li J, Orban C, Sabuncu MR, Liu H, Schaefer A, et al. (2019): Spatial Topography of IndividualSpecific Cortical Networks Predicts Human Cognition, Personality, and Emotion. Cereb Cortex. 29:25332551.

35. Liu J, Yuan B, Luo YJ, Cui F (2019): Intrinsic functional connectivity of medial prefrontal cortex predicts the individual moral bias in economic valuation partially through the moral sensitivity trait. Brain imaging 
bioRxiv preprint doi: https://doi.org/10.1101/2020.02.22.961136; this version posted February 25, 2020. The copyright holder for this preprint (which was not certified by peer review) is the author/funder, who has granted bioRxiv a license to display the preprint in perpetuity. It is made available under aCC-BY-NC-ND 4.0 International license.

and behavior.

36. Barnes KA, Anderson KM, Plitt M, Martin A (2014): Individual differences in intrinsic brain connectivity predict decision strategy. J Neurophysiol. 112:1838-1848.

37. Plitt M, Barnes KA, Wallace GL, Kenworthy L, Martin A (2015): Resting-state functional connectivity predicts longitudinal change in autistic traits and adaptive functioning in autism. Proc Natl Acad Sci U S A. 112:E6699-6706.

38. Li J, Kong R, Liegeois R, Orban C, Tan Y, Sun N, et al. (2019): Global signal regression strengthens association between resting-state functional connectivity and behavior. Neuroimage. 196:126-141.

39. Dubois J, Galdi P, Paul LK, Adolphs R (2018): A distributed brain network predicts general intelligence from resting-state human neuroimaging data. Philosophical transactions of the Royal Society of London Series B, Biological sciences. 373 .

40. Kashyap R, Kong R, Bhattacharjee S, Li J, Zhou J, Thomas Yeo BT (2019): Individual-specific fMRISubspaces improve functional connectivity prediction of behavior. Neuroimage. 189:804-812.

41. Dubois J, Galdi P, Han Y, Paul LK, Adolphs R (2018): Resting-state functional brain connectivity best predicts the personality dimension of openness to experience. Personal Neurosci. 1.

42. Cui Z, Gong G (2018): The effect of machine learning regression algorithms and sample size on individualized behavioral prediction with functional connectivity features. Neuroimage. 178:622-637.

43. Hou Y, Luo C, Yang J, Ou R, Song W, Wei Q, et al. (2016): Prediction of individual clinical scores in patients with Parkinson's disease using resting-state functional magnetic resonance imaging. J Neurol Sci. 366:27-32.

44. Yuan B, Zhang N, Yan J, Cheng J, Lu J, Wu J (2019): Resting-state functional connectivity predicts individual language impairment of patients with left hemispheric gliomas involving language network. NeuroImage Clinical. 24:102023.

45. Chen Q, Beaty RE, Cui Z, Sun J, He H, Zhuang K, et al. (2019): Brain hemispheric involvement in visuospatial and verbal divergent thinking. Neuroimage. 202:116065.

46. Lu X, Li T, Xia Z, Zhu R, Wang L, Luo YJ, et al. (2019): Connectome-based model predicts individual differences in propensity to trust. Hum Brain Mapp. 40:1942-1954.

47. Tang H, Lu X, Cui Z, Feng C, Lin Q, Cui X, et al. (2018): Resting-state Functional Connectivity and Deception: Exploring Individualized Deceptive Propensity by Machine Learning. Neuroscience. 395:101-112. 48. Nostro AD, Müller VI, Varikuti DP, Pläschke RN, Hoffstaedter F, Langner R, et al. (2018): Predicting personality from network-based resting-state functional connectivity. Brain Structure and Function.

49. Poole VN, Robinson ME, Singleton O, DeGutis J, Milberg WP, McGlinchey RE, et al. (2016): Intrinsic functional connectivity predicts individual differences in distractibility. Neuropsychologia. 86:176-182.

50. Wen T, Liu DC, Hsieh S (2018): Connectivity patterns in cognitive control networks predict naturalistic multitasking ability. Neuropsychologia. 114:195-202.

51. Wu X, Shi L, Wei D, Qiu J (2019): Brain connection pattern under interoceptive attention state predict interoceptive intensity and subjective anxiety feeling. Hum Brain Mapp. 40:1760-1773.

52. Long J, Huang X, Liao Y, Hu X, Hu J, Lui S, et al. (2014): Prediction of post-earthquake depressive and anxiety symptoms: a longitudinal resting-state fMRI study. Scientific reports. 4:6423.

53. Qin J, Shen H, Zeng LL, Jiang W, Liu L, Hu D (2015): Predicting clinical responses in major depression using intrinsic functional connectivity. Neuroreport. 26:675-680.

54. Li M, Wang D, Ren J, Langs G, Stoecklein S, Brennan BP, et al. (2019): Performing group-level functional image analyses based on homologous functional regions mapped in individuals. PLoS Biol. 17:e2007032.

55. Liu J, Liao X, Xia M, He Y (2018): Chronnectome fingerprinting: Identifying individuals and predicting higher cognitive functions using dynamic brain connectivity patterns. Hum Brain Mapp. 39:902-915.

56. Qin J, Shen H, Zeng L-L, Gao K, Luo Z, Hu D (2019): Dissociating individual connectome traits using 
bioRxiv preprint doi: https://doi.org/10.1101/2020.02.22.961136; this version posted February 25, 2020. The copyright holder for this preprint (which was not certified by peer review) is the author/funder, who has granted bioRxiv a license to display the preprint in perpetuity. It is made available under aCC-BY-NC-ND 4.0 International license.

low-rank learning. Brain research. 1722:146348-146348.

57. Wang D, Li M, Wang M, Schoeppe F, Ren J, Chen H, et al. (2018): Individual-specific functional connectivity markers track dimensional and categorical features of psychotic illness. Molecular psychiatry.

58. Brennan BP, Wang D, Li M, Perriello C, Ren J, Elias JA, et al. (2019): Use of an Individual-Level Approach to Identify Cortical Connectivity Biomarkers in Obsessive-Compulsive Disorder. Biol Psychiatry Cogn Neurosci Neuroimaging. 4:27-38.

59. Yoo K, Rosenberg MD, Hsu WT, Zhang S, Li CR, Scheinost D, et al. (2017): Connectome-based predictive modeling of attention: Comparing different functional connectivity features and prediction methods across datasets. Neuroimage. 167:11-22.

60. Yoshida K, Shimizu Y, Yoshimoto J, Takamura M, Okada G, Okamoto Y, et al. (2017): Prediction of clinical depression scores and detection of changes in whole-brain using resting-state functional MRI data with partial least squares regression. PloS one. 12:e0179638.

61. Meskaldji DE, Preti MG, Bolton TA, Montandon ML, Rodriguez C, Morgenthaler S, et al. (2016): Prediction of long-term memory scores in MCI based on resting-state fMRI. NeuroImage Clinical. 12:785795.

62. Cohen JR, Asarnow RF, Sabb FW, Bilder RM, Bookheimer SY, Knowlton BJ, et al. (2010): Decoding developmental differences and individual variability in response inhibition through predictive analyses across individuals. Frontiers in human neuroscience. 4:47.

63. Portugal LCL, Schrouff J, Stiffler R, Bertocci M, Bebko G, Chase H, et al. (2019): Predicting anxiety from wholebrain activity patterns to emotional faces in young adults: a machine learning approach. NeuroImage Clinical. 23:101813.

64. Bertolero MA, Yeo BTT, Bassett DS, D'Esposito M (2018): A mechanistic model of connector hubs, modularity and cognition. Nat Hum Behav. 2:765-777.

65. Yamashita M, Kawato M, Imamizu H (2015): Predicting learning plateau of working memory from whole-brain intrinsic network connectivity patterns. Scientific reports. 5:7622.

66. Yamashita M, Yoshihara Y, Hashimoto R, Yahata N, Ichikawa N, Sakai Y, et al. (2018): A prediction model of working memory across health and psychiatric disease using whole-brain functional connectivity. eLife. 7. 67. Fernandes O, Jr., Portugal LCL, Alves RCS, Arruda-Sanchez T, Rao A, Volchan E, et al. (2017): Decoding negative affect personality trait from patterns of brain activation to threat stimuli. Neuroimage. 145:337-345. 68. de Oliveira L, Portugal LCL, Pereira M, Chase HW, Bertocci M, Stiffler R, et al. (2019): Predicting Bipolar Disorder Risk Factors in Distressed Young Adults From Patterns of Brain Activation to Reward: A Machine Learning Approach. Biol Psychiatry Cogn Neurosci Neuroimaging.

69. Chen C, Yang J, Lai J, Li H, Yuan J, Abbasi N (2015): Correlating Gray Matter Volume with Individual Difference in the Flanker Interference Effect. PloS one. 10:e0136877.

70. Qin S, Young CB, Duan X, Chen T, Supekar K, Menon V (2014): Amygdala subregional structure and intrinsic functional connectivity predicts individual differences in anxiety during early childhood. Biological psychiatry. 75:892-900.

71. He N, Rolls ET, Zhao W, Guo S (2019): Predicting human inhibitory control from brain structural MRI. Brain imaging and behavior.

72. Hoexter MQ, Miguel EC, Diniz JB, Shavitt RG, Busatto GF, Sato JR (2013): Predicting obsessivecompulsive disorder severity combining neuroimaging and machine learning methods. Journal of affective disorders. 150:1213-1216.

73. Sato JR, Hoexter MQ, Oliveira PP, Jr., Brammer MJ, Consortium MA, Murphy D, et al. (2013): Interregional cortical thickness correlations are associated with autistic symptoms: a machine-learning approach. Journal of psychiatric research. 47:453-459.

74. Wang L, Wee CY, Suk HI, Tang X, Shen D (2015): MRI-based intelligence quotient (IQ) estimation with 
bioRxiv preprint doi: https://doi.org/10.1101/2020.02.22.961136; this version posted February 25, 2020. The copyright holder for this preprint (which was not certified by peer review) is the author/funder, who has granted bioRxiv a license to display the preprint in perpetuity. It is made available under aCC-BY-NC-ND 4.0 International license.

sparse learning. PloS one. 10:e117295.

75. Vo LT, Walther DB, Kramer AF, Erickson KI, Boot WR, Voss MW, et al. (2011): Predicting individuals' learning success from patterns of pre-learning MRI activity. PloS one. 6:e16093.

76. de Wit S, Ziermans TB, Nieuwenhuis M, Schothorst PF, van Engeland H, Kahn RS, et al. (2017): Individual prediction of long-term outcome in adolescents at ultra-high risk for psychosis: Applying machine learning techniques to brain imaging data. Hum Brain Mapp. 38:704-714.

77. He Q, Xue G, Chen C, Chen C, Lu ZL, Dong Q (2013): Decoding the neuroanatomical basis of reading ability: a multivoxel morphometric study. J Neurosci. 33:12835-12843.

78. Stonnington CM, Chu C, Kloppel S, Jack CR, Jr., Ashburner J, Frackowiak RS, et al. (2010): Predicting clinical scores from magnetic resonance scans in Alzheimer's disease. Neuroimage. 51:1405-1413.

79. Johnston BA, Steele JD, Tolomeo S, Christmas D, Matthews K (2015): Structural MRI-Based Predictions in Patients with Treatment-Refractory Depression (TRD). PloS one. 10:e0132958.

80. Wang Y, Fan Y, Bhatt P, Davatzikos C (2010): High-dimensional pattern regression using machine learning: From medical images to continuous clinical variables. Neuroimage. 50:1519-1535.

81. Tognin S, Pettersson-Yeo W, Valli I, Hutton C, Woolley J, Allen P, et al. (2013): Using structural neuroimaging to make quantitative predictions of symptom progression in individuals at ultra-high risk for psychosis. Frontiers in psychiatry. 4:187.

82. Mwangi B, Matthews K, Steele JD (2012): Prediction of illness severity in patients with major depression using structural MR brain scans. Journal of Magnetic Resonance Imaging. 35:64-71.

83. Zhu J, Zhu D-m, Zhang C, Wang Y, Yang Y, Yu Y (2019): Quantitative prediction of individual cognitive flexibility using structural MRI. Brain imaging and behavior. 13:781-788.

84. Eldar E, Hauser TU, Dayan P, Dolan RJ (2016): Striatal structure and function predict individual biases in learning to avoid pain. Proc Natl Acad Sci U S A. 113:4812-4817.

85. Corbetta M, Ramsey L, Callejas A, Baldassarre A, Hacker CD, Siegel JS, et al. (2015): Common behavioral clusters and subcortical anatomy in stroke. Neuron. 85:927-941.

86. Wei L, Guo N, Baeken C, Bi M, Wang X, Qiu J, et al. (2019): Grey Matter Volumes in the Executive Attention System Predict Individual Differences in Effortful Control in Young Adults. Brain Topogr. 32:111117.

87. Wang X, Baeken C, Fang M, Qiu J, Chen H, Wu GR (2018): Predicting trait-like individual differences in fear of pain in the healthy state using gray matter volume. Brain imaging and behavior.

88. Siegel JS, Ramsey LE, Snyder AZ, Metcalf NV, Chacko RV, Weinberger K, et al. (2016): Disruptions of network connectivity predict impairment in multiple behavioral domains after stroke. Proc Natl Acad Sci US A. 113:E4367-4376.

89. Moradi E, Hallikainen I, Hanninen T, Tohka J, Alzheimer's Disease Neuroimaging I (2017): Rey's Auditory Verbal Learning Test scores can be predicted from whole brain MRI in Alzheimer's disease. NeuroImage Clinical. 13:415-427.

90. Cui Z, Su M, Li L, Shu H, Gong G (2017): Individualized Prediction of Reading Comprehension Ability Using Gray Matter Volume. Cereb Cortex.1-17.

91. Moradi E, Khundrakpam B, Lewis JD, Evans AC, Tohka J (2017): Predicting symptom severity in autism spectrum disorder based on cortical thickness measures in agglomerative data. Neuroimage. 144:128-141.

92. Yang JJ, Yoon U, Yun HJ, Im K, Choi YY, Lee KH, et al. (2013): Prediction for human intelligence using morphometric characteristics of cortical surface: Partial least square analysis. Neuroscience. 246:351-361.

93. Bhagwat N, Pipitone J, Voineskos AN, Chakravarty MM, Alzheimer's Disease Neuroimaging I (2019): An artificial neural network model for clinical score prediction in Alzheimer disease using structural neuroimaging measures. Journal of psychiatry \& neuroscience : JPN. 44:246-260.

94. Yan J, Huang H, Risacher SL, Kim S, Inlow M, Moore JH, et al. (2013): Network-Guided Sparse Learning 
bioRxiv preprint doi: https://doi.org/10.1101/2020.02.22.961136; this version posted February 25, 2020. The copyright holder for this preprint (which was not certified by peer review) is the author/funder, who has granted bioRxiv a license to display the preprint in perpetuity. It is made available under aCC-BY-NC-ND 4.0 International license.

for Predicting Cognitive Outcomes from MRI Measures. Multimodal brain image analysis : third International Workshop, MBIA 2013, held in conjunction with MICCAI 2013, Nagoya, Japan, September 22, 2013 : proceedings / Li Shen, Tianming Liu, Pew-Thian Yap, Heng Huang, Dingg. 8159:202-210.

95. Yan JW, Li TY, Wang H, Huang H, Wan J, Nho K, et al. (2015): Cortical surface biomarkers for predicting cognitive outcomes using group 1(2,1) norm. Neurobiol Aging. 36:S185-S193.

96. Wan J, Zhang ZL, Rao BD, Fang SF, Yan JW, Saykin AJ, et al. (2014): Identifying the Neuroanatomical Basis of Cognitive Impairment in Alzheimer's Disease by Correlation- and Nonlinearity-Aware Sparse Bayesian Learning. Ieee T Med Imaging. 33:1475-1487.

97. Wang X, Zhen X, Li Q, Shen D, Huang H (2018): Cognitive Assessment Prediction in Alzheimer's Disease by Multi-Layer Multi-Target Regression. Neuroinformatics. 16:285-294.

98. Liu X, Cao P, Wang J, Kong J, Zhao D (2019): Fused Group Lasso Regularized Multi-Task Feature Learning and Its Application to the Cognitive Performance Prediction of Alzheimer's Disease. Neuroinformatics. 17:271-294.

99. Zhang Z, Allen GI, Zhu H, Dunson D (2019): Tensor network factorizations: Relationships between brain structural connectomes and traits. Neuroimage. 197:330-343.

100. Greening SG, Mitchell DG (2015): A network of amygdala connections predict individual differences in trait anxiety. Hum Brain Mapp. 36:4819-4830.

101. Powell MA, Garcia JO, Yeh FC, Vettel JM, Verstynen T (2018): Local connectome phenotypes predict social, health, and cognitive factors. Netw Neurosci. 2:86-105.

102. Rizk-Jackson A, Stoffers D, Sheldon S, Kuperman J, Dale A, Goldstein J, et al. (2011): Evaluating imaging biomarkers for neurodegeneration in pre-symptomatic Huntington's disease using machine learning techniques. NeuroImage. 56:788-796.

103. Feng C, Cui Z, Cheng D, Xu R, Gu R (2018): Individualized prediction of dispositional worry using white matter connectivity. Psychol Med.1-10.

104. Kawahara J, Brown CJ, Miller SP, Booth BG, Chau V, Grunau RE, et al. (2017): BrainNetCNN: Convolutional neural networks for brain networks; towards predicting neurodevelopment. Neuroimage. 146:1038-1049.

105. Jiang R, Calhoun VD, Cui Y, Qi S, Zhuo C, Li J, et al. (2019): Multimodal data revealed different neurobiological correlates of intelligence between males and females. Brain imaging and behavior.

106. Meng X, Jiang R, Lin D, Bustillo J, Jones T, Chen J, et al. (2017): Predicting individualized clinical measures by a generalized prediction framework and multimodal fusion of MRI data. Neuroimage. 145:218229.

107. Sui J, Qi S, van Erp TGM, Bustillo J, Jiang R, Lin D, et al. (2018): Multimodal neuromarkers in schizophrenia via cognition-guided MRI fusion. Nature communications. 9:3028.

108. Qi S, Sui J, Chen J, Liu J, Jiang R, Silva R, et al. (2019): Parallel group ICA+ICA: Joint estimation of linked functional network variability and structural covariation with application to schizophrenia. Hum Brain Mapp.

109. Boeke EA, Holmes AJ, Phelps EA (2019): Towards robust anxiety biomarkers: A machine learning approach in a large-scale sample. Biological Psychiatry: Cognitive Neuroscience and Neuroimaging.

110.Liu Z, Zhang J, Xie X, Rolls ET, Sun J, Zhang K, et al. (2018): Neural and genetic determinants of creativity. NeuroImage. 174:164-176.

111.Ullman H, Almeida R, Klingberg T (2014): Structural maturation and brain activity predict future working memory capacity during childhood development. J Neurosci. 34:1592-1598.

112.Zhu X, Suk HI, Shen D (2014): A novel matrix-similarity based loss function for joint regression and classification in AD diagnosis. Neuroimage. 100:91-105.

113.Zhang D, Shen D (2012): Predicting future clinical changes of MCI patients using longitudinal and 
multimodal biomarkers. PloS one. 7:e33182.

114. Yourganov G, Fridriksson J, Rorden C, Gleichgerrcht E, Bonilha L (2016): Multivariate ConnectomeBased Symptom Mapping in Post-Stroke Patients: Networks Supporting Language and Speech. J Neurosci. 36:6668-6679.

115.Cheng B, Zhang D, Chen S, Kaufer DI, Shen D, Alzheimer's Disease Neuroimaging I (2013): Semisupervised multimodal relevance vector regression improves cognitive performance estimation from imaging and biological biomarkers. Neuroinformatics. 11:339-353.

116. Wang Y, Goh JO, Resnick SM, Davatzikos C (2013): Imaging-based biomarkers of cognitive performance in older adults constructed via high-dimensional pattern regression applied to MRI and PET. PloS one. 8:e85460.

117.Fong AHC, Yoo K, Rosenberg MD, Zhang S, Li CR, Scheinost D, et al. (2018): Dynamic functional connectivity during task performance and rest predicts individual differences in attention across studies. Neuroimage. 188:14-25.

118.Kuceyeski A, Monohan E, Morris E, Fujimoto K, Vargas W, Gauthier SA (2018): Baseline biomarkers of connectome disruption and atrophy predict future processing speed in early multiple sclerosis. NeuroImage Clinical. 19:417-424.

119.Pustina D, Coslett HB, Ungar L, Faseyitan OK, Medaglia JD, Avants B, et al. (2017): Enhanced estimations of post-stroke aphasia severity using stacked multimodal predictions. Hum Brain Mapp. 38:56035615.

120. Yu G, Liu YF, Shen DG (2016): Graph-guided joint prediction of class label and clinical scores for the Alzheimer's disease. Brain Structure \& Function. 221:3787-3801.

121. Zhang DQ, Shen DG, Neuroimaging AsD (2012): Multi-modal multi-task learning for joint prediction of multiple regression and classification variables in Alzheimer's disease. Neuroimage. 59:895-907. 122. Liu X, Cao P, Yang J, Zhao D (2018): Linearized and Kernelized Sparse Multitask Learning for Predicting Cognitive Outcomes in Alzheimer's Disease. Computational and mathematical methods in medicine. 2018:7429782. 